\title{
Epigenetic modulators as therapeutic targets in prostate cancer
}

\author{
Inês Graça ${ }^{1,2}$, Eva Pereira-Silva', Rui Henrique ${ }^{1,3,4}$, Graham Packham ${ }^{5}$, Simon J. Crabb ${ }^{5}$ and Carmen Jerónimo ${ }^{1,4^{*}}$
}

\begin{abstract}
Prostate cancer is one of the most common non-cutaneous malignancies among men worldwide. Epigenetic aberrations, including changes in DNA methylation patterns and/or histone modifications, are key drivers of prostate carcinogenesis. These epigenetic defects might be due to deregulated function and/or expression of the epigenetic machinery, affecting the expression of several important genes. Remarkably, epigenetic modifications are reversible and numerous compounds that target the epigenetic enzymes and regulatory proteins were reported to be effective in cancer growth control. In fact, some of these drugs are already being tested in clinical trials. This review discusses the most important epigenetic alterations in prostate cancer, highlighting the role of epigenetic modulating compounds in pre-clinical and clinical trials as potential therapeutic agents for prostate cancer management.
\end{abstract}

Keywords: Prostate cancer, DNMTi, Histone modulators

\section{Background}

\section{Prostate cancer}

Prostate cancer (PCa) is one of the most common malignancies worldwide and a leading cause of cancer-related morbidity and mortality [1]. When diagnosed at early stages, it is potentially curable by radical prostatectomy or radiotherapy [2]. Furthermore, in many men, the disease is in fact indolent raising an important unmet need to better understand the biology of those prostate cancers that will never require exposure to treatment. However, for PCa that recurs after failure of primary surgery/radiotherapy or hormone-naive metastatic disease, androgen deprivation therapy (ADT), combined with docetaxel chemotherapy in suitably fit patients, is the mainstay of treatment [3-5]. Gonadotropin-releasing hormone $(\mathrm{GnRH})$ agonists or antagonists, initially combined with anti-androgens (e.g., bicalutamide), are used to lower androgen levels, leading to tumor remission and a decline in serum

\footnotetext{
* Correspondence: carmenjeronimo@ipoporto.min-saude.pt;

cljeronimo@icbas.up.pt

'Cancer Biology and Epigenetics Group—Research Center (CI-IPOP),

Portuguese Oncology Institute of Porto (IPO-Porto), Research Center-LAB 3, F Bdg, 1st floor, Rua Dr. António Bernardino de Almeida, 4200-072 Porto, Portugal

${ }^{4}$ Department of Pathology and Molecular Immunology, Institute of Biomedical Sciences Abel Salazar-University of Porto (ICBAS-UP), Porto, Portugal

Full list of author information is available at the end of the article
}

prostate-specific antigen (PSA). Although nearly all patients respond to ADT, for patients with metastatic cancer progression to a lethal stage of the disease, termed castration-resistant prostate cancer (CRPC), occurs in virtually all patients after a median of 11 months $[6,7]$. Despite previously being termed "hormone refractory" in fact, CRPC normally remains, at least initially, critically dependent on androgen receptor (AR) signaling. The mechanisms underlying castration resistance relating to the AR itself include receptor amplification, activating mutations, constitutively active truncating splice variants, phosphorylation, and methylation. Persistent transcriptional AR activity can also be mediated by altered responsiveness to, or increased expression of, alternative ligands including progesterone and corticosteroids or by adrenal production of androgens that is not responsive to $\mathrm{GnRH}$ agonists/antagonists, as well as intraprostatic testosterone and dihydrotestosterone (DHT) synthesis [8]. Finally, components of the activated AR complex, including epigenetic mediators as described in this review, may be overexpressed (co-activators) or repressed (co-repressors) and other signaling pathways may also be activated, for example, including the MAPK, PI3K/Akt, and Wnt pathways $[9,10]$. For metastatic CRPC (mCRPC), treatment with next-generation hormonal therapies, such as the CYP17A1 inhibitor abiraterone which depletes androgen 
synthesis pathway precursors or the AR antagonist enzalutamide, is an option; however, acquired resistance inevitably arises (within 1-2 years in the pre-docetaxel setting) $[11,12]$. It is becoming increasingly clear that this clinical phenotype is commonly characterized by therapeutic cross resistance, at least between available hormonal therapies, making sequential use of limited benefit, and that current treatment options drive the emergence of treatmentresistant clonally convergent subpopulations $[13,14]$. For mCRPC, other agents that have an established survival benefit include chemotherapy with either docetaxel or cabazitaxel combined with prednisone, the radiopharmaceutical radium-223, and the autologous cellular immunotherapy sipuleucel T [15-19]. Unfortunately, none of these agents are curative and the median survival from the point of transition to mCRPC is 2-3 years [7], strengthening the urgent need for investigation of new therapeutic approaches.

\section{DNA methylation and histone modifications in prostate cancer}

$\mathrm{PCa}$ is a complex and heterogeneous disease that arises from both genetic and epigenetic alterations [20]. Concerning epigenetic modifications, DNA methylation is the best well-studied epigenetic alteration [21]. It consists of the addition of a methyl group by DNA methyltransferases (DNMTs): DNMT1, DNMT3A, and DNMT3B, donated by $S$-adenosylmethionine (SAM), to cytosine residues within CpG dinucleotides. Whereas DNMT1 ensures the maintenance of tissue-specific methylation patterns over cellular replication, DNMT3A and DNMT3B are involved in the maintenance and de novo methylation of DNA strands [22, 23]. Aberrant alterations of the methylation patterns are common features of $\mathrm{PCa}$ development and progression (Fig. 1). Global DNA hypomethylation increases as the disease progresses, with a lower overall content of 5methylcytosine $\left(\mathrm{m}^{5} \mathrm{C}\right)$ found in metastatic tissues [24], promoting chromosome instability, activation of retrotransposons, and aberrant gene expression. Loss of imprinting of IGF2 (with consequent biallelic expression) was found in cancerous as well as in associated histologically normal peripheral zone prostatic tissue, which indicates that it might predispose the development of carcinogenesis over a long latency period [25]. Promoter hypomethylation may result in the activation of proto-oncogenes, although this is a relatively underexplored event. One example is urokinase plasminogen activator (PLAU), a gene involved in tumor invasion and metastasis and whose expression has been associated with CRPC [26]. Heparanase, an endo- $\beta$-D-glucuronidase, is also highly expressed in $\mathrm{PCa}$, especially in metastatic lesions, but not in prostatic intraepithelial neoplasia (PIN) [27]. Conversely, DNA hypermethylation at specific gene loci is a key molecular hallmark of PCa. In fact, this is one of the first aberrations, seen as early as in pre-invasive lesions, such as PIN, and persisting throughout disease progression [28]. Tumor suppressor genes silenced by promotor hypermethylation in $\mathrm{PCa}$ are involved in important cellular pathways, including cell cycle control, apoptosis, DNA damage repair or hormonal response. Thus far, more than 100 genes have been shown to be inactivated by promoter hypermethylation in $\mathrm{PCa}$. Remarkably, glutathione S-transferase pi 1 (GSTP1), a gene involved in DNA repair, is hypermethylated in more than $90 \%$ of PCa cases, as well as in over $50 \%$ of PCa precursor lesions, suggesting this as an early event in prostate carcinogenesis [29-32]. Methylation of Ras association domain family protein 1, isoform A (RASSF1A) promoter was strongly correlated with an increased risk of $\mathrm{PCa}$ recurrence, aggressiveness, and tumor progression [33, 34]. Progression to CRPC was also linked with AR silencing by hypermethylation [35]. In fact, AR hypermethylation was described in about $30 \%$ of CRPC [36]. Several other genes were described as frequently hypermethylated in morphologically normal prostate tissue and in PIN (e.g., ATP binding cassette subfamily $\mathrm{B}$ member $1(A B C B 1)$, adenomatous polyposis coli $(A P C)$, cyclin D2 (CCND2), O-6-methylguanine-DNA methyltransferase (MGMT), retinoic acid receptor beta 2 (RARB2), RASSF1A, prostaglandin-endoperoxide synthase 2 (PTGS2)) further implicating DNA hypermethylation in PCa initiation [37-39].

In addition to DNA methylation, histone modifications were also implicated in prostate carcinogenesis (Fig. 1). The $\mathrm{N}$-terminal tails of histones may undergo a variety of post-translational covalent modifications, which are catalyzed by various histone-modifying enzymes (Fig. 2). At least 16 different post-translational modifications (PTMs) have been reported, including acetylation, methylation, phosphorylation, ubiquitination, and glycosylation [40]. These changes constitute the "histone code" which acts as a layer of epigenetic regulation of gene expression affecting chromatin structure and remodeling [41]. In general, acetylation enables transcriptional activity and is catalyzed by histone acetyltransferases (HAT). Conversely, histone deacetylases (HDACs) remove acetyl groups leading to condensed and repressive chromatin. In PCa, HDAC 1, 2, and 3 are strongly expressed, especially in CRPC [42, 43]. Moreover, HDAC1 and HDAC2 were found to be highly expressed in PCa with high Gleason score and might be correlated with increased proliferative capacity [43] but only HDAC2 expression has been associated with shorter PCa patient relapse-free survival time after radical prostatectomy. Additionally, HATs and HDACs may change the acetylation status of non-histone proteins, such as AR [44]. Indeed, AR co-activators and co-repressors influence transcriptional activity by regulating AR itself or its responsive genes, via their respective HAT or HDAC activities. Acetylation of coactivators enhances the transcriptional activity of AR facilitating its binding to 


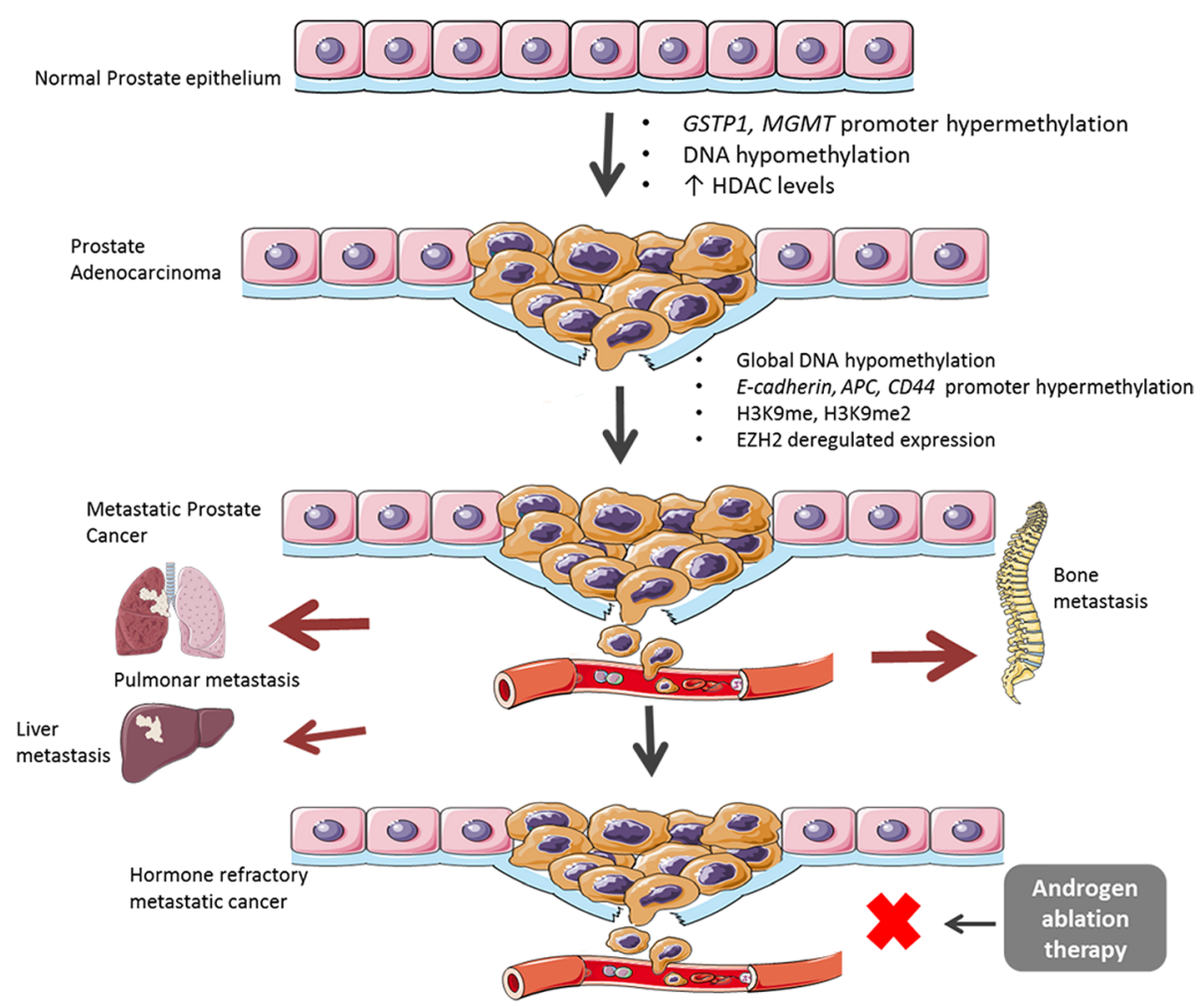

Fig. 1 Epigenetic alterations involved in PCa development and progression. Several epigenetic aberrations, as silencing of tumor suppressor genes by promoter hypermethylation, aberrant expression of histone modulating proteins, and DNA hypomethylation contribute not only to PCa onset but also to its progression to advanced and castration-resistant cancer

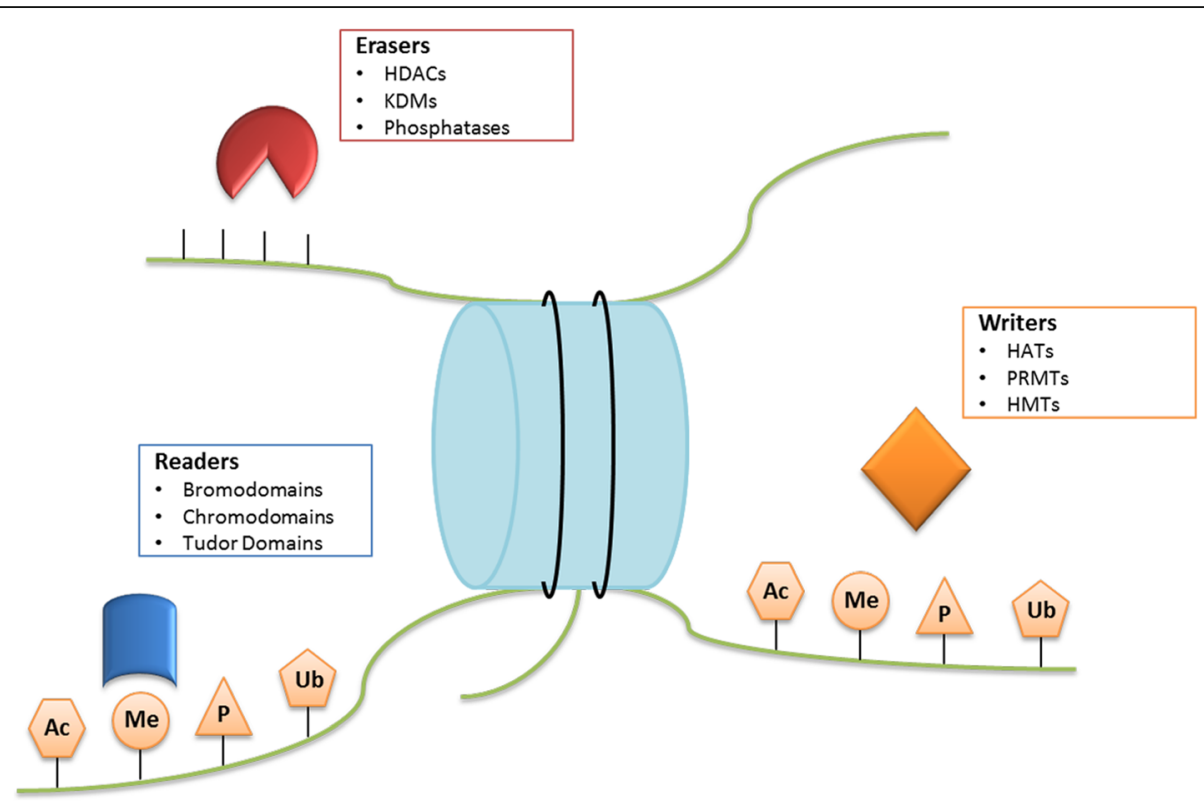

Fig. 2 Writers, Erasers, and Readers. Epigenetic Writers (HATs, HDMs, and PRMTs) are responsible to establish epigenetic marks on amino acid residues of histone tails. Epigenetic Erasers (HDACs, KDMs and phosphatases) participate on the removal of the epigenetic marks. Epigenetic Readers (bromodomain, chromodomain and Tudor domain proteins) recognize and bind to a specific epigenetically modified mark 
target DNA sequences. Contrarily, AR activity is abrogated by HDAC1, HDAC2, and sirtuin 1 (SIRT1) [45]. SIRT1 was shown to be downregulated in $\mathrm{PCa}$, compared to normal prostatic tissue, leading to H2A.Z overexpression and consequent upregulation of $\mathrm{v}$-myc avian myelocytomatosis viral oncogene homolog $(M Y C)$ and other oncogenes [46].

Histone methylation may be associated with transcriptional activation or repression, depending on the amino acid residue and the number of methyl groups added. Specifically, methylation of lysines 4, 36, and 79 of histone 3 (H3K4me3, H3K36me, and H3K79me) are marks of active transcription, whereas methylation of lysines 9 and 27 of histone 3 (H3K9 and H3K27) results in silent chromatin state [40, 47]. In PCa, H3K4me, H3K9me2, H3K 9me3, and acetylation of $\mathrm{H} 3$ and $\mathrm{H} 4$ were shown to be reduced in comparison with non-malignant tissue. It was also demonstrated that CRPC patients displayed increased levels of H3K4me, H3K4me2, and H3K4me3 [48]. In fact, high levels of lysine-specific demethylase 1A (KDM1A) was correlated with increased risk for disease relapse [49] and AR function [50]. The histone methyltransferase (HMT) polycomb protein enhancer of zeste homolog 2 (EZH2) is by far the most studied epigenetic enzyme in PCa. This enzyme, responsible for H3K27 trimethylation, was found to be overexpressed in $\mathrm{PCa}$, particularly in mCRPC [51] and was associated with promoter hypermethylation and repression of some tumor suppressor genes, suggesting its involvement in $\mathrm{PCa}$ progression [51, 52]. Interestingly, in CRPC, the oncogenic role of EZH2 was independent of its polycomb transcriptional repressor activity, functioning as a co-activator of several transcription factors such as AR [53]. Thereby, epigenetic deregulation of co-activators may contribute to failure of androgen deprivation therapy in $\mathrm{PCa}$ patients. Lysine-specific demethylase 1 (LSD1) is another enzyme involved in prostate carcinogenesis. It acts both as co-activator and co-repressor of transcription by targeting H3K4 or H3K9, respectively $[49,54,55]$. In fact, LSD1 was found to form a complex with AR, stimulating its activity. Moreover, increased levels of LSD1 were associated with aggressive CRPC and high risk of disease relapse [49, 55].

Several other histone-modifying enzymes, like JHDM2A, JMJD2C, SET9, and SMYD3 have already been shown to play a role in prostate carcinogenesis [50, 56-59]. Moreover, in addition to changes in chromatin modifier enzymes, some histone modifying patterns, like H3K18Ac, H3K4me2, and H3K4me1 were also associated with increased risk for PCa recurrence $[48,60]$.

\section{Evidence acquisition}

We searched PubMed for publications on $\mathrm{PCa}$ and epigenetic therapy using the keywords: prostate cancer, DNA methylation, histone modifications, epigenetic drugs, DNMT inhibitors, HDAC inhibitors, histone modulators, HAT inhibitors, histone demethylase (HDM) inhibitors, and every drug mentioned on the manuscript, on January 15, 2016. Only articles written in English were retrieved. Original reports were selected based on the detail of analysis, mechanistic support of data, novelty, and potential clinical usefulness of the findings. A total of 283 papers were included in this review.

\section{Epigenetic silencing as a therapeutic target in prostate cancer}

The interest in epigenetic modulators as targets for cancer therapy has been growing in recent years (Fig. 3) [61]. Indeed, six epigenetic compounds that target either DNA methylation or histone deacetylation have already been approved by the Food and Drug Administration (FDA) for cancer treatment (Table 1) [62-68]. Herein, we will focus on the advances of the use of DNMT inhibitors (DNMTi) and histone modulators for PCa therapy.

\section{DNMT inhibitors}

Among the epigenetic inhibitors, DNMTi are those in more clinically advanced stage of development. This family of compounds, depending on the mode of action, is divided in two classes: nucleoside and non-nucleoside inhibitors $[69,70]$.

Nucleoside analogues are composed of a modified cytosine ring that is attached to either a ribose or deoxyribose moiety and, therefore, can be incorporated into DNA or RNA, replacing cytosines. When incorporated into DNA during replication, these drugs covalently bind and capture DNMTs on the DNA strand. DNMTs are subsequently depleted due to passive demethylation during continuous replication. These agents induce cell death by obstructing DNA synthesis and/or inducing DNA damage through structural instability at the sites of incorporation $[69,71]$. The two most studied nucleoside analogues are 5-azacytidine, a ribose nucleotide which is mostly incorporated into RNA interfering with protein synthesis, and 5-aza-2'-deoxycytidine which is incorporated preferentially into DNA. These DNMTi are approved for treatment of Myelodysplastic syndrome (MDS) and are currently in clinical trials in a range of other cancers [72]. However, azanucleosides have some pitfalls, including their higher instability and their short half-life owing to fast degradation by cytidine deaminase [69, 73]. Zebularine was shown to be more stable and less toxic than the 5-azanucleosides, since it was able to inhibit cytidine deaminase, it incorporates only in DNA via the ribonucleotide reductase pathway and induced minimal toxic effects in animals $[74,75]$. This compound has proven anti-proliferative activity in cell lines and induces cancer cell death through 


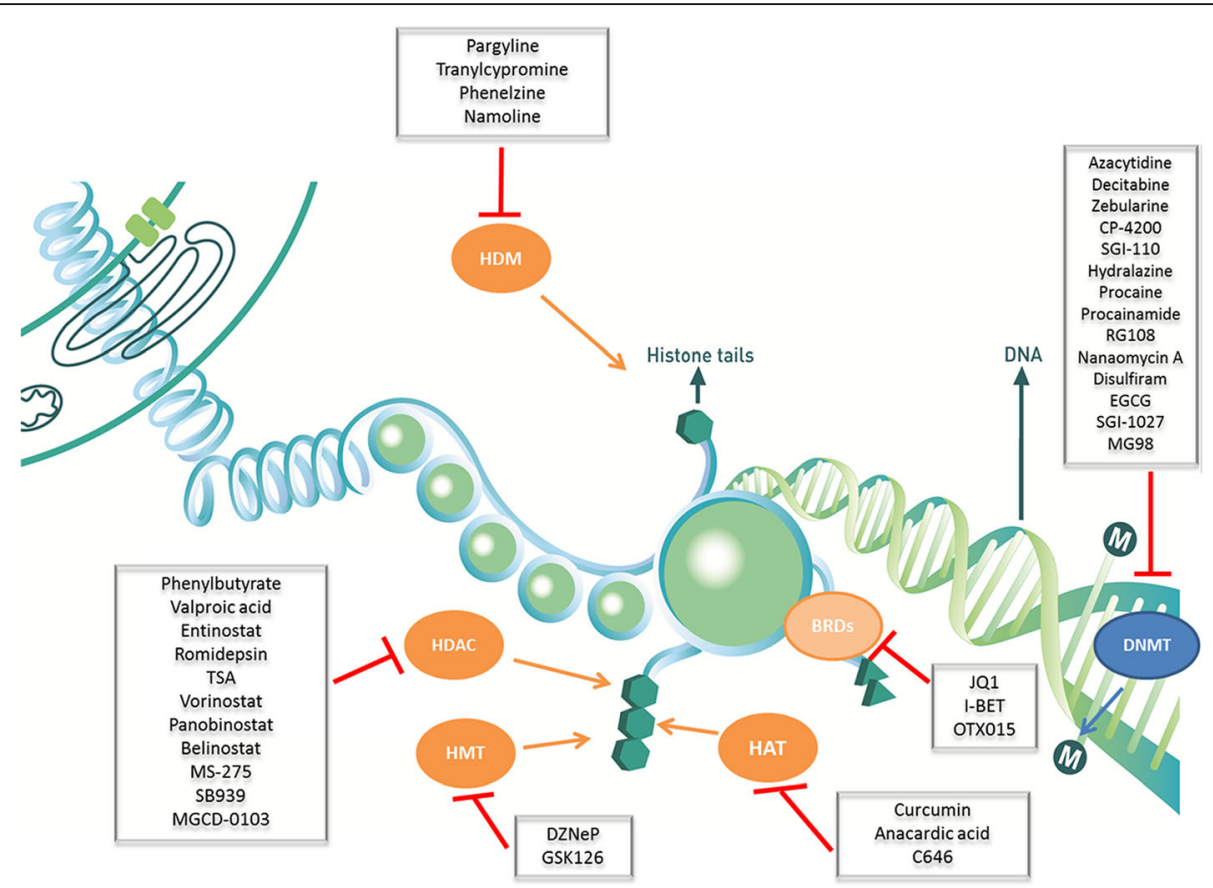

Fig. 3 Epigenetic modifying drugs. This figure illustrates several epigenetic compounds classified accordingly to their respective epigenetic target that have been reported as having a role on PCa cell phenotype reversion either in pre-clinical or clinical assays

alterations in DNA methylation status [74, 76-78]. CP4200 , an elaidic acid ester analog of 5 -azacytidine, is a nucleoside transporter-independent drug which has shown superior efficacy to 5-azacytidine in an orthotopic acute lymphocytic leukemia (ALL) mouse tumor model [79] and was recently shown to overcome 5 -azacytidine resistance mechanisms related to the cellular uptake in leukemia cells [80]. SGI-110 (guadecitabine) is a dinucleotide of 5-aza-2'-deoxycytidine and deoxyguanosine which confers relative resistance to cytidine deaminase and so an enhanced exposure to the active 5-aza-2'-deoxycytidine moiety. It was reported to be effective in inhibiting DNA methylation both in vitro and in vivo, and also acts as an immune modulator [81, 82]. Moreover, a phase I clinical trial showed good tolerance as well as clinical and biologic activity in MDS and acute myeloid leukemia (AML) patients [83].

One major limitation of nucleoside analogues is the requirement for DNA incorporation and active DNA synthesis, which limits the activity of these drugs in hypoproliferative cancers. This may be the major reason for their limited efficacy in the majority of solid tumors [84]. Because the nucleoside analogues are intrinsically cytotoxic, several efforts are being made to discover compounds that directly target DNMTs, without requiring prior incorporation into DNA. Presently, the non-

Table 1 Epigenetic drugs for cancer therapy approved by FDA

\begin{tabular}{|c|c|c|c|c|c|c|}
\hline Drug & Comercial name & Company & Class & Year of approval & Treatment type & Cancer \\
\hline 5-Azacytidine & Vidaza $^{\oplus}$ & Celgene Corporation & DNMTi & 2004 & Single agent & $\begin{array}{l}\text { Myelodysplastic } \\
\text { syndrome }\end{array}$ \\
\hline $\begin{array}{l}\text { 5-Aza-2'- } \\
\text { deoxycytidine }\end{array}$ & $\operatorname{Dacogen}^{\oplus}$ & Eisai & DNMTi & 2006 & Single agent & $\begin{array}{l}\text { Myelodysplastic } \\
\text { syndrome }\end{array}$ \\
\hline Vorinostat/SAHA & Zolinza® & Merck & Pan-HDACi & 2006 & Single agent & $\begin{array}{l}\text { Cutaneous T cell } \\
\text { lymphoma }\end{array}$ \\
\hline Romidepsin & Istodax ${ }^{\circledR}$ & Celgene Corporation & Class I HDACi & 2009 & Single agent & $\begin{array}{l}\text { Cutaneous and peripheral } \\
\text { T cell lymphoma }\end{array}$ \\
\hline Belinostat & Beleodaq $^{\oplus}$ & $\begin{array}{l}\text { Spectrum } \\
\text { Pharmaceuticals, Inc. }\end{array}$ & Pan-HDACi & 2014 & Single agent & $\begin{array}{l}\text { Peripheral T cell } \\
\text { lymphoma }\end{array}$ \\
\hline Panobinostat & Farydak $^{\circledast}$ & Novartis & Pan-HDACi & 2015 & $\begin{array}{l}\text { Combination with bortezomid } \\
\text { and examethasone }\end{array}$ & Multiple myeloma \\
\hline
\end{tabular}


nucleoside family includes compounds that have already been approved by FDA for non-neoplastic conditions, specifically hydralazine (anti-hypertensive drug), procaine (local anesthetic), and procainamide (anti-arrhythmic drug) and small molecules designed to directly block the active site of human DNMTs, like RG108. The major advantage of the former class is that the pharmacodynamic profile is well-known, and their adaptation for cancer therapy may be more cost-effective. The latter class, moreover, exhibits higher specificity, since the compounds are designed for direct enzyme inhibition $[69,73]$.

Hydralazine is a potent arterial vasodilator drug whose demethylating activity was suspected based in one of its secondary effects: the induction of Lupus-like syndrome [85-87]. Hydralazine was shown to induce tumor suppressor genes' demethylation/reactivation in several cancer models and its activity is synergized with that of the histone deacetylase inhibitors (HDACi) valproic acid, both in vitro and in vivo [88-90]. Several clinical trials using hydralazine in combination with valproic acid in MDS and in solid tumors demonstrated no significant toxic effects [91-93]. Procaine and procainamide are two closely related small molecules that have been proposed to function as DNMTi also due to their ability to bind CpGrich sequences, thereby interfering with DNMTs binding. Procainamide specifically inhibits DNMT1 but not DNMT3a and $3 \mathrm{~b}$, suggesting that this drug might be a highly specific inhibitor [94]. Both procaine and procainamide were reported to reduce DNA methylation in cancer cells $[95,96]$. The antibiotic nanaomycin A was recently reported as a selective inhibitor of DNMT3b, with the ability to reduce methylation and induce expression of the tumor suppressor gene RASSF1A [97]. Disulfiram, a drug used in the clinics for the treatment of alcohol abuse, was described as a DNMT inhibitor with the ability to decrease the global levels of 5methylcytosine, as well as to demethylate and reactivate the expression of epigenetically silenced tumor suppressor genes [98, 99]. SGI-1027, a quinoline-based compound, has demonstrated inhibitory activity against DNMT1, DNMT3a, and DNMT3b, possibly by interacting with the DNA substrate, which results in demethylation and reactivation of tumor suppressor genes [100]. RG108 was the first DNMTi designed to directly inhibit DNMT1 catalytic site. In fact, this compound was able to inhibit DNMT activity in a cell-free assay and to reduce global methylation levels in human cancer cells. [101-103]. Recently, this compound was also reported to induce differentiation of promyelocytic leukemia cells in combination with HDACi $[104,105]$. MG98, a 20-bp anti-sense oligonucleotide, whose sequence is complementary to 3 '-untranslated region (UTR) of DNMT1, was developed to block the translation of this enzyme [106]. Despite the DNMT1 inhibitory activity displayed in xenograft mouse models and in some patients, this compound did not achieve significant response in clinical trials [107-109]. Soy isoflavones (e.g., genistein) and their metabolites are also DNMTs inhibitors, with promising roles in cancer prevention and treatment [110]. The green tea polyphenol, (-)-epigallocatechin3-O-gallate (EGCG) is an anti-tumoral agent that targets DNA methylation through DNMTs' inhibition [111].

\section{Pre-clinical activity of DNMT inhibitors in prostate cancer}

In a pre-clinical assay, PCa cells chronically exposed to 5-aza-2'-deoxycytidine for 21 days, exhibited a marked decrease in tumor cell proliferation and AR reactivation, with concomitantly increased PSA protein levels. The restoration of AR-sensitized CRPC cells in xenograft models to the anti-androgen bicalutamide [112, 113]. 5-Aza-2' deoxycytidine was able to decrease PCa stem-cellness and induce cell differentiation. In vitro and in vivo assays demonstrated that AR re-expression by 5-aza-2' -deoxycytidine led to in vitro and in vivo suppression of PCa stem cell proliferation, decreasing PCa tumorigenesis [114]. Zeburaline was able to restore GST-pi and GST-mu expression, both in vitro and in xenografts, enhancing the activity of brostallicin, a DNA minor groove binder with anti-cancer activity [115]. Additionally, PCa cell lines and xenografted mice exposed to procainamide demonstrated a reversion of GSTP1 hypermethylation, with concomitant gene reexpression [96]. However, one study comparing the two non-nucleoside inhibitors with 5-aza-2'-deoxycytidine in PCa cell lines, demonstrated that 5-aza-2'-deoxycytidine was considerably more effective in demethylating and reactivating tumor suppressor genes [116]. Recently, synthesized procainamide conjugates proved to be more potent inhibitors of murine catalytic Dnmt3A/3L complex and human DNMT1, decreasing DU145 cell viability more efficiently than the parent compound [117]. Concerning RG108, we have demonstrated a dose- and timedependent growth inhibition and apoptosis induction in LNCaP, 22Rv1, and DU145 PCa cell lines. This compound repressed DNMT activity and expression, reducing global DNA methylation in androgen-responsive PCa cells. Furthermore, exposure of LNCaP and 22Rv1 to RG108 significantly decreased promoter methylation levels of GST $P 1, A P C$, and $R A R-\beta 2$, although mRNA re-expression was only achieved for GSTP1 and APC [118]. We have also recently demonstrated that hydralazine was able to restrain PCa cell growth and promote apoptosis in a time and dose dependent manner. Moreover, hydralazine decreased cellular invasiveness and induced cell cycle arrest and DNA damage in PCa cell lines. Additionally, PCa cells exposed to hydralazine exhibited lower DNMT1, DNM T3a, and DNMT3b mRNA levels as well as lower DNMT1 protein, which may have contributed to the observed decrease in GSTP1, B cell CLL/lymphoma 2 (BCL2) and $C C N D 2$ promoter methylation levels, and concomitant 
gene re-expression. Importantly, hydralazine restored AR expression and upregulation of its target protein p21, in DU145 cells. The attenuation of tumor phenotype was particularly effective in the castration-resistant PCa cell line DU145, and this feature was associated with epidermal growth factor (EGF) receptor signaling disruption [119]. SGI-1027 was able to entirely deplete DNMT1 expression in LNCaP cells [100]. SGI-1027 and two analogues (paralmeta and metalmeta) inhibited effectively PC-3 proliferation and viability, at concentration of $100 \mu \mathrm{M}$ [120]. Mahanine, a plant-derived carbazole alkaloid, inhibits DNMT activity inducing RASSF1A expression in LNCaP and PC-3 cells [121]. Moreover, this drug also inhibited LNCaP and PC-3 cells' proliferation and induced apoptosis [122]. In a large study, the DNMT inhibitory effect of 1120 compounds was evaluated, from which 12 were selected for cytotoxicity tests in DU145 cells. Remarkably, the majority of the compounds with activity at low micromolar concentration displayed very limited cytotoxicity [123]. Genistein reduced RAR $\beta 2$, RASSF1A, and GSTP1 promoter methylation, entailing gene re-expression in $\mathrm{PCa}$ cell lines $[124,125]$. Interestingly, this compound was able not only to reduce estrogen receptor- $\beta(E R-\beta)$ promoter methylation, with corresponding increase in $E R$ $\beta$ expression, but also decrease LNCaP and LAPC-4 cell proliferation [126]. Likewise, EGCG through DNMT1 activity inhibition induced re-expression of transcriptionally silenced genes in PCa cell lines [127, 128]. Finally, disulfiram exposure promoted PCa cells apoptosis and cell- cycle arrest, reduced tumor volume in xenograft mice, and restored expression of tumor suppressor genes, $A P C, R A R$ $\beta$ and $E R-\beta$ through inhibition of DNMT activity $[99,129]$.

\section{Clinical evaluation of DNMT inhibitors in prostate cancer}

Although aberrant DNA promoter methylation is a major phenomenon in prostate carcinogenesis, there are only a few clinical trials testing DNMTi in PCa patients (Table 2). A phase II trial (NCT00384839) testing 5-azacytidine enrolled 36 PCa patients. PSA-doubling time (DT) less than 3 months was recorded in 19 patients, and the overall median PSA-DT was prolonged compared to baseline (2.8 vs. 1.5 months). One patient showed a $30 \%$ PSA decline, whereas in 14 patients, only a slight PSA decline was observed. Grade 3 toxicities were reported and four patients had to stop therapy. DNA LINE-1 methylation levels in plasma were also significantly decreased [130]. In a small phase II clinical trial, in which 14 patients with mCRPC were enrolled, 5-aza- 2 '-deoxycytidine was administered intravenously every $8 \mathrm{~h}$ at a dose of $75 \mathrm{mg} / \mathrm{m}^{2}$, every 5 to 8 weeks. Although well tolerated, only two patients showed disease stabilization with delayed time to progression for as long as 10 weeks [131].

\section{Histone modulators (HDAC, HMTs, HDMi, and BET inhibitors)}

Several compounds with the ability to modulate the expression of key enzymes involved in establishing (writers), removing (erasers), and maintaining (readers) epigenetic

Table 2 DNMT inhibitors in clinical trials for PCa

\begin{tabular}{|c|c|c|c|c|c|c|}
\hline Drug & $\begin{array}{l}\text { Clinical } \\
\text { trial ID }\end{array}$ & Phase & Status & Protocol & Outcome & Ref. \\
\hline 5-Azacytidine (Vidaza) & NCT00384839 & $\|$ & Completed & $\begin{array}{l}\text { Patients with CRPC received } 75 \mathrm{mg} / \mathrm{m}^{2} \\
\text { of } 5 \text {-azacytidine for five consecutive days } \\
\text { of a } 28 \text {-day cycle. Patients were treated } \\
\text { until clinical progression up to a maximum } \\
\text { of } 12 \text { cycles. } n=36\end{array}$ & $\begin{array}{l}\text { 5-Azacytidine modulates PSA } \\
\text { (doubling time }>3 \text { months) in } \\
56 \% \text { of patients. Clinical } \\
\text { progression-free survival of } 12.4 \text { weeks }\end{array}$ & [130] \\
\hline $\begin{array}{l}\text { 5-Aza-2-deoxycytidine } \\
\text { (decitabine) }\end{array}$ & - & $\|$ & Completed & $\begin{array}{l}14 \text { patients with metastatic prostate } \\
\text { cancer recurrent after total androgen } \\
\text { blockade and flutamide withdrawal } \\
\text { received three doses of } \\
5 \text {-aza-2-deoxycytidine infusion } \\
\left(75 \mathrm{mg} / \mathrm{m}^{2}\right) \text {. Cycles of therapy were } \\
\text { repeated every } 5 \text { to } 8 \text { weeks. } n=14\end{array}$ & $\begin{array}{l}\text { Two of } 12 \text { patients evaluable for } \\
\text { response had stable disease with a } \\
\text { time to progression of more than } \\
10 \text { weeks. Modest clinical activity }\end{array}$ & [131] \\
\hline $\begin{array}{l}\text { 5-Azacytidine, } \\
\text { docetaxel, and } \\
\text { prednisone }\end{array}$ & NCT00503984 & $|/| \mid$ & $\begin{array}{l}\text { Ongoing } \\
\text { not recruiting }\end{array}$ & $\begin{array}{l}\text { mCRPC patients, who progressed } \\
\text { during or within } 6 \text { months of docetaxel } \\
\text { chemotherapy, were eligible. In phase I, } \\
5 \text {-azacytidine and docetaxel were } \\
\text { alternately escalated in a three weekly } \\
\text { cycle. All patients received prednisone } \\
5 \text { mg twice daily continuously. } n=22\end{array}$ & $\begin{array}{l}\text { Toxicity: myelosuppression } \\
\text { Reduction in GADD-45 } \\
\text { methylation on day } 5\end{array}$ & [273] \\
\hline $\begin{array}{l}\text { 5-Azacytidine, } \\
\text { phenylbutyrate }\end{array}$ & NCT00006019 & $\|$ & Completed & $\begin{array}{l}\text { Patients received } 5 \text {-azacytidine } \\
\text { subcutaneously on days } 1-7 \text { and } \\
\text { phenylbutyrate I.v. over } 1-2 \text { h on days } 8-12 \text {. } \\
\text { Additional course was repeated every } \\
21 \text { to } 28 \text { days in the absence of disease } \\
\text { progression or unacceptable toxicity. } n=20\end{array}$ & Not available & \\
\hline
\end{tabular}


profiles have been identified as promising therapeutic tools for PCa (Fig. 3) [61, 132].

\section{HDAC inhibitors}

HDACs overexpression is a common feature of human malignancies. Therefore, targeting HDACs has been a major research area in cancer therapy; although to date, the established clinical utility has remained rather modest. Thus far, various structurally different compounds have been tested in a broad range of cancers [133]. By altering the expression of several genes and/or function of several proteins, HDACi disrupt cancer cell pathways, such as cell proliferation, angiogenesis, differentiation, and apoptosis, culminating in cell cytotoxicity. In general, HDACi contain a zinc-binding domain connected by a straight chain linker to a capping group [134, 135]. HDCAi are chemically classified into different subgroups based on their structure: aliphatic acids (phenylbutyrate, sodium butyrate, and valproic acid), benzamides (mocetinostat and entinostat), cyclic peptides (romidepsin, largazole) and hydroxamic acids (trichostatin A (TSA), vorinostat/suberoylanilide hydroxamic acid (SAHA), belinostat, panobinostat) [136, 137]. Several, dietary phytochemicals (e.g., sulforaphane, phenethyl isothiocyanate) also inhibit HDAC activity suggesting anti-tumoral properties [138]. However, HDAC targeting is quite complex because they have multiple subclasses, some of which with yet unknown functions and mechanisms of action [133, 139]. Furthermore, enzymatic activity of HDACs is not restricted to histones, but extends to several other proteins [140].

\section{HAT inhibitors}

Histone acetyltransferases inhibitors (HATi) have gained interest due to promising anti-cancer results in pre-clinical models of solid tumors [141]. Nevertheless, the discovery and design of selective HATi with high efficacy remains a challenge [142]. Currently, this family of compounds comprises four distinct classes: bisubstrate inhibitors, natural compounds and their analogues and derivatives, synthetic small molecules, and bromodomain inhibitors [142]. Curcumin, a component of Curcuma longa rhizome, is a specific inhibitor of $\mathrm{p} 300 / \mathrm{CREB}$-binding protein that inhibits acetylation of p53 in vivo [143]. This compound is currently under evaluation in clinical trials for colorectal (NCT01859858, NCT00745134, NCT02724202, and NCT 02439385) and breast (NCT01740323 and NCT01975363) cancers. CTK7A (hydrazinobenzoylcurcumin) is a watersoluble inhibitor of p300 and several other proteins that reduce xenograft tumor growth in mice [144]. Anacardic acid, a non-specific HATi of p300, isolated from the liquid of cashew nut shells, also demonstrated anti-cancer activity through modulation of nuclear factor kappa B (NF-kB) pathway [145]. Garcinol, a micromolar inhibitor of p300 and P300/CBP-associated factor (PCAF) obtained from
Garcinia indica, displays anti-tumor activity by inducing apoptosis and inhibiting autophagy of human cancer cells [146, 147]. Plumbagin, a potent KAT3B/p300 inhibitor isolated from Plumbago rosea, decreased tumor cell growth, angiogenesis, and invasion in several cancer models [148-151]. With a similar scaffold, Embelin, isolated from Embelia ribes, specifically inhibits H3K9 acetylation and also displays anti-tumor activity [152154]. NK13650A and NK13650B are two novel compounds with anti-cancer activity that have been extracted from a Penicillium strain, demonstrating a strict p300 selectivity [155]. C646 is synthetic small selective molecule inhibitor of $\mathrm{p} 300 / \mathrm{CBP}$ that was shown to induce apoptosis in cancer cells through inhibition of AR and NF-kB pathway $[156,157]$. Two other synthetic compounds, NU9056 and TH1834, are specific micromolar inhibitors of TIP60 (KAT5) acetyltransferase activity [158, 159].

\section{HMT and HDM inhibitors}

HMTs and HDMs are emerging as a novel field of epigenetic actionable molecules with clinical interest. Several new compounds are currently under evaluation to assess their specificity for targeted epigenetic therapy and its anti-cancer effectiveness [160-162]. These compounds are thought to be more attractive than HDACi because they can eliminate selective histone marks, which in turn might enable a better tailored therapy, minimizing undesirable side effects.

Among histone methyltransferase inhibitor (HMTi), 3-dezaneplanocin-A (DZNeP) stands as a $S$-adenosylL-homocysteine (AdoHcy) hydrolase inhibitor which converts adenosyl-L-homocysteine, produced by methyltransferases, in adenosine and homocysteine. S-Adenosylmethionine (AdoMet), a methyl donor for methylation reactions, is metabolized to AdoHcy by methyltransferases. By increasing AdoHcy levels, DZNeP inhibits methyltransferases. This compound was first reported as EZH2 inhibitor, decreasing H3K27 trimethylation, but is currently considered a global HMTi [163, 164]. DZNeP downregulates EZH2, reactivates several tumor suppressor genes inhibited by polycomb repressive complex 2 (PRC2), and inhibits cancer cell phenotype $[163,165,166]$. GSK126 is a small molecule that inhibits methyltransferase activity of both wild-type and mutant EZH2, is independent of substrate, and, more importantly, is extremely selective against other methyltransferases and/or other proteins $[167,168]$. Like DZNeP, this compound reduces global H3K27me3 levels and induces expression of silenced PRC2 target genes. GSK126 reduced the proliferation of cancer cells lines and inhibited tumor growth in xenografts [168-170]. EPZ-6438 (tazemetostat) is also an effective and orally bioavailable EZH2 inhibitor with anti-cancer activity [171]. Other novel EZH2 inhibitors are currently under clinical trial, namely CPI-1205 (NCT02395601), E7438 (NCT018 
97571), tazemetostat (NCT02601937 and NCT02601950), and GSK2816126 (NCT02082977).

LSD1 inhibitors represent the family of histone demethylase inhibitors (HDMi) most studied thus far, and the majority of the assays were performed with non-selective amine oxidase (MAO) inhibitors (pargyline, tranylcypromine, and phenelzine). These compounds irreversibly react with flavin adenine dinucleotide (FAD) through a radical mechanism, forming a tetracyclic adduct, and were originally designed for treatment of psychiatric illnesses. Presently, they are under investigation for cancer therapy due to their ability to block LSD1 [55, 172-174]. Namoline was reported as a selective and reversible inhibitor of LSD1, with in vitro and in vivo activity, that might interfere with global histone methylation levels [175].

\section{BET inhibitors}

Bromodomain (BET) proteins bind to acetylated histones, increase proliferation, and may lead to overexpression of several oncogenes such as MYC [176]. JQ1 and I-BET (I-BET762 or GSK525762) are novel compounds that inhibit bromodomain proteins competing with its binding to histone acetylated lysine residues, which results in the displacement of BET proteins from acetylated chromatin [177]. Both compounds were shown to induce cellular differentiation, senescence, and apoptosis [178]. JQ1 showed selectivity for the BET family, with higher affinity for Bromodomain-Containing Protein 4 (BRD4) and demonstrated anti-tumor activity in several cancer cell types [179-181]. I-BET, also a diazepine-based compound with proved in vitro and in vivo anti-cancer activity, is currently in phase I clinical trials for hematological malignancies (NCT01943851) and solid tumors (NCT01587703) [182, 183]. OTX015, a novel oral inhibitor of BRD2/3/4, derivative of JQ1 that was originally developed for the treatment of inflammatory bowel disease, also demonstrated in vitro and in vivo anti-neoplastic efficacy and is currently in phase I clinical trials for hematological malignancies (NCT01713582) and several solid tumors (NCT02259114), as well as in a phase IIa trial for glioblastoma multiform (NCT02296476) $[177,184,185]$. I-CBP112, that targets CBP/p300 bromodomains, induces differentiation, cell cycle arrest, and suppresses tumor proliferation $[186,187]$.

\section{Pre-clinical activity of $\mathrm{HDACi}$ in prostate cancer}

Several HDACi demonstrated encouraging results in preclinical phase studies, showing promise as candidates for future clinical trials.

Concerning the aliphatic acids family, exposure to sodium butyrate induced growth inhibition and increased differentiation and apoptosis of PC-3 and DU145 cells $[188,189]$. Remarkably, treatment with sodium butyrate also induced H2B acetylation, and methylation on multiples lysine residues, as well as phosphorylation of Thr19, in DU145 cells [190]. Recently, this compound was shown to stimulate the morphological and molecular differentiation of LNCaP cells via inhibition of T-type $\mathrm{Ca}^{2+}$ channels [191]. Valproic acid (VPA) also reduced cell viability and induced apoptosis in vitro and was able to reduce tumor growth in xenograft models [192]. Moreover, this compound inhibited epithelial-mesenchymal transition (EMT) and invasion abilities of PC-3 cells by decreasing SMAD4 protein expression and upregulating the metastasis suppressor gene $\mathrm{N}$-myc downstream regulated gene-1 (NDRG1), respectively [193, 194]. In a TRAMP model of PCa treated with VPA, decreased tumor growth and invasiveness correlated with the re-expression of $C C N D 2$, a frequently silenced gene in PCa [195]. Remarkably, this compound also induced AR and E-cadherin expression in PCa cell lines [196].

Among hydroxamic acids, vorinostat/SAHA demonstrated the ability to decrease $\mathrm{PCa}$ cell lines proliferation and to reduce tumor growth in vivo [197, 198]. Panobinostat also induced cell cycle arrest and DNA damage and reduced PCa tumor growth in vivo [199]. Moreover, the exposure of $\mathrm{PCa}$ cells to this compound lead to a decrease in $A R$ levels and reversed resistance to hormone therapy in castration-resistant PCa cell lines [200]. Belinostat showed pronounced anti-tumor effects in androgenresponsive PCa cell lines increasing p21, p27, and p53 protein expression and leading to G2/M cell cycle arrest [201]. It also reduced the migration of PCa cells, increasing the expression of tissue inhibitor of metalloproteinase-1 (TIMP-1). Moreover, it decreased the expression of oncogenic proteins, such as mutant P53 and ERG. Notably, the cytotoxic activity of this compound was preferentially directed against tumor cells [202].

Concerning the cyclic peptides family, mice inoculated with the $22 \mathrm{Rv} 1$ cell line exposed to romidepsin not only experienced reduced metastasis formation but also induces a $61 \%$ survival increase [203]. Largazole and 2-epi-largazole are potent class I-selective HDACi, purified from marine cyanobacteria, that decrease LNCaP and PC-3 cell viability [204].

The benzamide derivative MS-275 increased H3 acetylation, p21 protein expression, and induced growth arrest in LNCaP and PC-3 cells and apoptosis in DU145 cells. Moreover, MS-275 reduced tumor growth in xenograft mice [205], particularly when acting synergistically with radiation therapy [206]. This drug also lead to H3K4 methylation upregulation, inducing re-expression of tumor suppressor and cell differentiation genes [207].

Sulforaphane, an isothiocyanate isolated form broccoli, suppressed PCa tumor cell growth in male nude mice and significantly correlated with decreased HDAC activity in prostate tissue and mononuclear blood cells. Moreover, in human subjects, the consumption of BroccoSprouts (68 g) also inhibited HDAC activity in peripheral blood mononuclear cells [208]. Importantly, another study 
demonstrated that sulforaphane effects are selective, since it more potently induced cell cycle arrest apoptosis and acetylation of $\mathrm{H} 3$ at $P 21$ promoter and inhibited HDAC activity in benign hyperplasia (BPH1) and cancer (LNCaP and PC-3) PCa cells than in the normal cell line PrEC [209]. It was also reported that this compound destabilizes AR by hyperacetylating HSP90, via restraining HDAC6, leading to AR proteasomal degradation [210]. Recently, it was shown that sulforaphane was able to decrease MYC expression, the activity of aldehyde dehydrogenase 1 (ALDH1), CD49f + fraction enrichment and the efficiency of sphere forming, all characteristics of $\mathrm{PCa}$ stem cells [211]. Phenethyl isothiocyanate (PEITC), another isothiocyanate, suppressed $\mathrm{PCa}$ progression in transgenic adenocarcinoma of mouse prostate mice by induction of autophagic cell death and overexpression of E-cadherin [212]. Another study demonstrated that PEITC suppressed androgen-responsive tumor growth in vivo, possibly by downregulation of integrin family proteins $(\beta 1, \alpha 2$, and $\alpha 6)$ and tumor platelet/endothelial cell adhesion molecule (PECAM-1/CD31) [213]. This compound also promoted apoptosis and cell cycle arrest and inhibited invasion and on in vitro and in vivo models of PCa [214-216]. Like sulforaphane, PEITC repressed AR transcription and expression [217].

New specific HDAC1 inhibitors designed and synthetized using click chemistry revealed anti-proliferative activity in DU145 cells at micromolar concentrations [218]. A specific inhibitor of HDAC6, N-hydroxy-4(2-[(2-hydroxyethyl)(phenyl)amino]-2-oxoethyl)benzamide (HPOB) decreased viability of LNCaP cells without affecting cell death or causing DNA damage. Furthermore, this compound inhibited HDAC6 deacetylase activity but not its ubiquitin-binding activity and incremented the cell death effect of SAHA, etoposide, and doxorubicin [219]. A novel compound, 3-hydroxypyridin-2-thione (a non-hydroxamate chemotype), was able to reduce expression of HDAC6 and 8 and suppress viability of LNCaP cells. This might be due, in part, to induced hyperacetylation of Hsp90 that subsequently attenuates interactions of key proteins essential for LNCaP cells survival, such as AR [220]. New class IIselective hydroxamate inhibitors, that target HDAC4 and HDAC6, were effective in decreasing cell proliferation and inducing cell cycle arrest at G1 phase and nuclear histone acetylation of PC-3 and LNCaP cells [221]. Benzothiazolecontaining analogues of vorinostat/SAHA compounds displayed not only anti-proliferative effects in PC-3 cells but it also reduced tumor growth in a PC-3 mouse xenograft with efficacy equivalent to vorinostat/SAHA [222].

Development of hybrid compounds that could modulate multiple targets with superior efficacy and fewer side effects than current single-target drugs is underway [133]. A new set of HDACi were generated to selectively accumulate in PCa cells. A non-steroidal anti-androgen scaffold based on cyanonilutamide was incorporated into a prototypical HDACi (vorinostat/SAHA) pharmacophore, creating an AR-HDACi which will first engage AR, selectively accumulate, and then released to engage HDACs. These compounds demonstrated improved inhibition of all HDACs' activity compared to vorinostat/ SAHA alone and were able to simultaneously antagonize AR. Moreover, they displayed anti-proliferative activity in AR-expressing cell lines [223]. Another hybrid compound that resulted from the combination of methotrexate and hydroxamate (methotrexate-caproic hydroxamic acid) reduced HDAC activity and decreased viability of $\mathrm{PC}-3$ cells [224]. Additionally, a new drug, VPA-GFLG-iRGD, which conjugates VPA with a cell penetrating peptide (iRGD) and a lysosomally degradable tetrapeptide (-GlyPheLeuGly-, -GFLG-), induced a significant decrease in the proportion of DU145 cells in G2 phase with increased cytotoxicity. This might be related with RGB induced blockage of $\alpha_{v} \beta_{3}$ and $\alpha_{v} \beta_{5}$ integrin on DU145 cell surface [225]. Likewise, the synthesis of dual-acting histone deacetylase (vorinostat/SAHA) and topoisomerase II inhibitors (anthracycline daunorubicin) resulted in decreased proliferation of DU145 cells [226]. Recently, WJ35435, a hybrid vorinostat/SAHA and DACA (topoisomerase inhibitor) molecule with anti-HDAC activity, showed a more potent anti-cancer effect, inducing more potent cell cycle arrest, DNA damage and apoptosis, than either agent alone, in PC-3 and DU-145 cells. Furthermore, this compound revealed anti-tumor activity in vivo and, importantly, it did not affect benign prostate cells [227]. Recently, CUDC-101, which resulted from the incorporation of HDAC inhibitory functionality into the pharmacophore of epidermal growth factor receptor (EGFR) and human epidermal growth factor receptor 2 (HER2)/NEU inhibitors [228], was able to reduce $A R$ and $A R-v 7$ expression, $\mathrm{PCa}$ cell proliferation in vitro and in vivo [229]. This compound is currently in phase I trial in solid tumors (NCT01702285).

\section{Clinical trials testing $\mathrm{HDACl}$ in prostate cancer}

Several HDACi are under clinical trial for $\mathrm{PCa}$ treatment (Table 3). A phase II clinical trial (NCT00330161) with vorinostat/SAHA was conducted in MCRPC patients with disease progression and previously treated with chemotherapy [230]. Patients were daily treated with orally administrated $400 \mathrm{mg}$ vorinostat/SAHA. The best objective response was stable disease in 2 out of the $27(7 \%)$ patients enrolled in this trial. Median time to progression was 2.8 months, with a median overall survival of 11.7 months. Grade 3 or 4 toxicities (fatigue, nausea, vomiting, anorexia, diarrhea, and weight loss) were experienced by $48 \%$ of patients and 11 (41\%) actually discontinued therapy due to toxicity. Thus, vorinostat/SAHA at this schedule had marginal therapeutic efficacy, and this might be associated with the substantial toxicities described. 
Table 3 Histone modifying drugs in clinical trials for PCa

\begin{tabular}{|c|c|c|c|c|c|c|}
\hline Drug & Clinical trial ID & Phase & Status & Protocol & Outcome & Ref. \\
\hline Vorinostat/SAHA & NCT00330161 & $\|$ & Completed & $\begin{array}{l}\text { Metastatic PCa with disease } \\
\text { progression on prior chemotherapy } \\
\text { received } 400 \mathrm{mg} \text { vorinostat/SAHA } \\
\text { orally each day. Disease progression } \\
\text { measured at } 6 \text { months. } n=27\end{array}$ & $\begin{array}{l}\text { Toxicity: significant toxicities including } \\
\text { fatigue, nausea. IL-6 (Interleukin 6) was } \\
\text { higher in patients with toxicity. } 7 \% \\
\text { patients achieved a stable disease state. } \\
\text { No PSA decline }>50 \% \text { observed. Median } \\
\text { time to progression and overall survival } \\
\text { were } 2.8 \text { and } 11.7 \text { months, respectively. } \\
\text { Significant toxicities reported. }\end{array}$ & {$[230]$} \\
\hline Vorinostat/SAHA & NCT00005634 & 1 & Completed & $\begin{array}{l}\text { Patients with advanced or metastatic } \\
\text { solid tumors that have not responded } \\
\text { to previous therapy received } \\
\text { vorinostat/SAHA I.v. on days } 1-3 \text { every } \\
\end{array}$ & $\begin{array}{l}\text { Determine the tolerability, pharmacokinetic } \\
\text { profile, and biologic effects of the drug. } \\
\text { Not available }\end{array}$ & \\
\hline
\end{tabular}

$\begin{array}{lll}\begin{array}{l}\text { Vorinostat/SAHA } \\ \text { and docetaxel }\end{array} & \text { NCT00565227 } & \text { I }\end{array}$

21 days. $n=45$

and docetaxe

Patients with advanced and relapsed tumors received oral vorinostat/SAHA for the first 14 days of a 21-day cycle, with docetaxel I.V. on day 4 of each cycle. $n=12$

$\begin{array}{lll}\begin{array}{l}\text { Vorinostat/SAHA } \\ \text { and doxorubicin }\end{array} & \text { NCT00331955 I Completed } & \text { Patients receive oral vorinostat/SAHA } \\ & \text { twice daily for } 5 \text { doses on days 1-3, } \\ & 8-10 \text { and } 15-17 \text { and doxorubicin I.v. on } \\ & \text { days } 3,10, \text { and } 17 \text { very } 28 \text { days for up } \\ & \text { to } 6 \text { courses. } n=32\end{array}$

Vorinostat/SAHA and androgen

NCT00589472 ॥ Completed

Localized $\mathrm{PCa}$ patients received

deprivation therapy

(ADT)

Vorinostat/SAHA
and mTOR inhibitor

NCT01174199 | Ongoing, not

temsirolimus

recruiting

Panobinostat

NCT00667862 ॥ Completed

Panobinostat

(LBH589), docetaxel

NCT00663832 | Completed

neo-adjuvant vorinostat/SAHA with oral bicalutamide with either I.M. leuprolide or subcutaneous goserelin acetate administered for up to 8 weeks or until the day of surgery. $n=19$

Toxicity: neutropenia, peripheral neuropathy, and gastrointestinal bleeding. The combination of vorinostat/SAHA and docetaxel was poorly tolerated. No responses were identified.

Partial response was achieved in one of the two PCa patients enrolled.

Metastatic PCa patients received oral vorinostat once daily on days 1-14 and temsirolimus intravenously on days 1,8 , and 15 of a 21 -day cycle. $n=13$

I.v. panobinostat $(20 \mathrm{mg} / \mathrm{m} 2)$ was administered to CRPC patients on days 1 and 8 of a 21-day cycle. Disease progression measured at

24 weeks. $n=35$

CRPC patients received oral panobinostat $(20 \mathrm{mg} / \mathrm{m} 2)$ on days 15 for 2 consecutive weeks. On the other arm, patients received oral panobinostat $(15 \mathrm{mg} / \mathrm{m} 2)$ with docetaxel I.v. $(75 \mathrm{mg} / \mathrm{m} 2)$ every 21 days and oral prednisone $(5 \mathrm{mg})$ twice every day of a 21 -day cycle. $n=16$

Panobinostatbicalutamide NCT00878436 I/II Completed

Men with CRPC received treatment with bicalutamide (50 mg PO) daily with oral panobinostat at 2 dose levels (20 or $40 \mathrm{mg}$ ). Minimum treatment was 3 weeks $n=9$

Panobinostat docetaxel NCT00493766

Terminated because of a In one arm, oral panobinostat alone and prednisone along with I.V. docetaxel and ora prednisone is administered. $n=16$

$\begin{array}{lllll}\begin{array}{l}\text { Panobinostat, } \\ \text { docetaxel, } \\ \text { and prednisone }\end{array} & \text { NCT00419536 } & \text { I } & \begin{array}{l}\text { Terminated } \\ \text { because of a } \\ \text { strategic decision }\end{array} & \text { Not available } \\ \begin{array}{l}\text { Panobinostat, } \\ \text { radiotherapy }\end{array} & \text { NCT00670553 } & \text { C } & \text { Completed } & \begin{array}{l}\text { Not available. } \\ n=7\end{array}\end{array}$

Romidepsin

NCT00106418 || Completed

MCRPC patients received romidepsin $(13 \mathrm{mg} / \mathrm{m} 2)$ intravenously on days 1,8 , and 15 every 21 -day cycle. Disease progression measures at 6 months. $n=35$

Patients with CRPC were continued at the same dose of romidepsin as in the previous study, which could have been $13 \mathrm{mg} / \mathrm{m} 2$ or a reduced dose of $10 \mathrm{mg} / \mathrm{m} 2$, on days 1,8 , and 15 of each 28-day cycle. $n=2$
Determine the rate of pathologic complete response in patients with localized PCa treated with ADT and vorinostat/SAHA before radical prostatectomy measuring androgens in blood. Not available

Determine the safety, tolerability, partial and complete objective response rates, progression-free survival and overall survival, and PSA response. Not available

Toxicity: fatigue, thrombocytopenia, nausea $14 \%$ patients demonstrated a decrease in PSA but none $>50 \%$. No clinical activity.

Toxicity: dyspnea and neutropenia Panobinostat in combination with docetaxel and prednisone in patients with CRPC resulted in $63 \%$ of patients with $>50 \%$ decline in PSA levels. No relevant anti-tumor activity.

Toxicity: thrombocytopenia In 2 patients, it was registered

a $>50 \%$ PSA decline by

9 months of therapy; and

3 patients presented stable

PSA levels.

Toxicity: dyspnea, neutropenia, fatigue. Exposure to oral panobinostat was similar with and without docetaxel.

Determine maximum tolerated dose of panobinostat and to characterize the safety, biological activity, and pharmacokinetic profile.

Establish toxicity, tolerability, and safety of oral panobinostat when given in combination with radiotherapy. Not available

Toxicity: nausea, fatigue

2 patients reached a confirmed radiological partial response of over 6 months, in addition to $>50 \%$ PSA decline. 11 patients had to discontinue the therapy due to toxicity. Romidepsin demonstrated minimal anti-tumor activity in chemonaive patients with CRPC.

Evaluate adverse effects and effect of romidepsin and evaluate the time of disease progression. Not available 
Table 3 Histone modifying drugs in clinical trials for PCa (Continued)

\begin{tabular}{|c|c|c|c|c|}
\hline $\begin{array}{l}\text { Romidepsin in solid } \\
\text { tumors with liver } \\
\text { dysfunction }\end{array}$ & NCT01638533 & I & $\begin{array}{l}\text { Currently } \\
\text { recruiting } \\
\text { patients }\end{array}$ & $\begin{array}{l}\text { Patients with recurrent prostate } \\
\text { carcinoma receive romidepsin I.v. on } \\
\text { days } 1,8 \text {, and } 15 \text {. Courses repeat every } \\
28 \text { days in the absence of disease } \\
\text { progression or unacceptable toxicity. } \\
n=132\end{array}$ \\
\hline Pracinostat & NCT01075308 & $\|$ & Completed & $\begin{array}{l}\text { Recurrent or mCRPC patients received } \\
\text { pracinostat orally }(60 \mathrm{mg}) 3 \text { times a } \\
\text { week for } 3 \text { consecutive weeks followed } \\
\text { by } 1 \text { week off-dosing of a } 28 \text {-day cycle. } \\
n=32\end{array}$ \\
\hline
\end{tabular}

Valproic acid

NCT00670046

Not provided

Non-metastatic with biochemical progression PCa patients received ora valproic acid twice daily for up to 1 year in the absence of disease progression or unacceptable toxicity. $n=50$

Valproic acid and NCT00530907 I Completed
bevacizumab

\begin{tabular}{|c|c|c|c|}
\hline Sulforaphane & NCT01228084 & $\|$ & Completed \\
\hline Sulforaphane & - & $\|$ & Completed \\
\hline $\begin{array}{l}\text { MGCD-0103 and } \\
\text { docetaxel }\end{array}$ & NCT00511576 & । & Terminated \\
\hline Curcumin & NCT02064673 & $\|$ & Recruiting \\
\hline $\begin{array}{l}\text { Curcumin, prednisone, } \\
\text { and docetaxel }\end{array}$ & - & ॥ & \\
\hline $\begin{array}{l}\text { Curcumin and } \\
\text { radiotherapy }\end{array}$ & NCT01917890 & $\begin{array}{l}\text { Not } \\
\text { provided } \\
\text { (pilot) }\end{array}$ & Completed \\
\hline
\end{tabular}

Curcumin and taxotere

Phenelzine
NCT02095717 ॥ Recruiting

mCRCP patients receive taxotere plus curcumin capsule vs taxotere plus placebo. $n=100$

Recurrent non-metastatic PCa received phenelzine daily and orally during 12 months. $n=46$
Bevacizumab was administered at escalating dosages of $2.5-11 \mathrm{mg} / \mathrm{kg}$ on days 1 and 15, and oral valproic acid at dosages of $5.3-10 \mathrm{mg} / \mathrm{kg}$ on days $1-28$ every 28. $n=57$
Establish the safety and tolerability,

pharmacokinetics, and maximum

tolerated dose. Not available

Toxicity: fatigue, neutropenia

2 patients achieved a decline $>50 \%$ of PSA. In patients with measurable disease, there were no objective responses, while 7 patients had stable disease lasting 1.7 to 8 months.

Percentage of patients exhibiting observed or predicted PSA doubling time $>10$ months after initiation of the study. Not available

Toxicities: grade 3 altered mental status $(n=2)$, related to valproic acid. Bevacizumab $11 \mathrm{mg} / \mathrm{kg}$ given on days 1 and 15 and valproic acid $5.3 \mathrm{mg} / \mathrm{kg}$ daily were the recommended phase II dosages. Stable disease $\geq 6$ months were reported in $4 / 57$ of patients. Of the 39 patients evaluated for histone acetylation, 2 of 3 (67\%) patients with stable disease $\geq 6$ months showed histone acetylation, while 8 of 36 ( $22 \%$ ) without stable disease $\geq 6$ months demonstrated histone acetylation $(p=0.16)$. Patients with hypertension had improved overall survival.

1 patient experienced $a \geq 50 \%$ PSA decline and 7 patients had PSA declines $>50 \%$. No grade 3 events reported.

Sulforaphane-treated patients presented $86 \%$ longer PSA-DT than the placebo group. Increases $>20 \%$ of PSA levels higher in the placebo group $(71.8 \%)$ compared to the sulforaphane-treated group (44.4\%)

Determine the maximum tolerated dose, dose limiting toxicities and safety profile of escalating doses of oral MGCD-0103 in of escalating doses of oral MGCD-0 docetaxel. Not available

Determine recurrence-free survival as total PSA $<0.2 \mathrm{ng} / \mathrm{ml}$. Not available were submitted to a radical prostatectomy received oral curcumin or placebo 500 mg twice a day for 6 months. $n=600$

Patients with progressing CRPC and a rising Decreased PSA levels were observed in $\mathrm{PSA}$ received docetaxel/prednisone for 6 cycles in combination with curcumin $6000 \mathrm{mg} /$ day (day -4 to day +2 of PCa patients undergo 74 Gy radiotherapy 5 times a week for 7-8 weeks and take $3 \mathrm{~g}$ of curcumin vs placebo. $n=40$ $59 \%$ of patients and $40 \%$ of evaluable patients presented a partial respon
The regimen was well tolerated.

The change in urinary symptoms across the 20-week period differed significantly between groups $(p=0.011)$ and patients in the curcumin group experienced much milder urinary symptoms compared with the placebo group. Curcumin could not reduce the severity of bowel symptoms or other treatment-related symptoms. PSA levels were reduced to below $0.2 \mathrm{ng} / \mathrm{ml}$ in both groups.

Assess time to progression of metastatic disease by tumor response rate, increase in PSA levels ( $\geq 25 \%$ and $\geq 2 \mathrm{ng} / \mathrm{ml}$ increase) or the appearance of new lesions metastatic. Not available

Determine biochemical recurrent prostate cancer by PSA decline to $\geq 50 \%$ following at least 12 weeks of treatment. Not available 
Table 3 Histone modifying drugs in clinical trials for PCa (Continued)

\begin{tabular}{|c|c|c|c|c|c|}
\hline $\begin{array}{l}\text { Phenelzine and } \\
\text { docetaxel }\end{array}$ & NCT01253642 & $\|$ & Recruiting & $\begin{array}{l}\text { PCa patients with progressive disease after } \\
\text { first-line therapy with docetaxel received } \\
\text { phenelzine orally once a day on days }-7 \\
\text { to }-4 \text { and twice a day on days }-3 \text { to } 21 \\
\text { and docetaxel I.v. on day } 1 \text {. Treatment } \\
\text { repeats every } 21 \text { days for at least } \\
12 \text { weeks. } n n=30\end{array}$ & $\begin{array}{l}\text { Determine the proportion of patients who } \\
\text { experience a PSA decline of at least } 30 \% \\
\text { and duration of progression-free survival. } \\
\text { Not available }\end{array}$ \\
\hline OTX015 & NCT02259114 & IB & Recruiting & $\begin{array}{l}\text { Advanced solid tumors including CRPC. } \\
\text { Patients divided in two regimens: ( } 1 \text { ) } \\
\text { continuous, once daily for } 21 \text { consecutive } \\
\text { days and ( } 2 \text { ) once daily on days } 1 \text { to } 7 \text {, } \\
\text { repeated every } 3 \text { weeks ( } 1 \text { week on } / 2 \\
\text { weeks off). } n=98\end{array}$ & $\begin{array}{l}\text { Determine maximum tolerated dose and the } \\
\text { number of dose limiting toxicity. Not available }\end{array}$ \\
\hline
\end{tabular}

Recently, a phase II clinical trial evaluated the efficacy of panobinostat in CRPC patients (NCT00667862) with disease progression after chemotherapy [231]. The rate of progression-free survival (PFS) at 24 weeks was set as primary endpoint. Thirty-five patients received $20 \mathrm{mg} / \mathrm{m}^{2}$ of panobinostat intravenously on days 1 and 8 of a 21-day cycle. No objective responses were documented. Four patients $(11.4 \%)$ did not show progression of disease at 24 weeks. All patients experienced grade 3 and 4 toxicities. Therefore, it was concluded that PCa treatment with panobinostat alone was insufficient to achieve clinical efficacy [231]. A phase II study with romidepsin was conducted in 35 metastatic CRPC patients (NCT00106418). Romidepsin was administrated intravenously at $13 \mathrm{mg} / \mathrm{m}^{2}$ on days 1,8 , and 15 of a 28-day cycle [232]. Partial response confirmed by radiology and PSA decline was achieved in two patients. Eleven patients, however, experienced significant drug toxicity and discontinued therapy. With this drug schedule, romidepsin demonstrated minimal anti-tumor activity in mCRPC patients.

A recent phase II trial with pracinostat (NCT01075308), an orally active hydroxamic acid, enrolled 32 CRPC patients, which received $60 \mathrm{mg}$ three times per week, on alternate days, for three weeks, followed by one-week resting period. The drug was well tolerated, and confirmed PSA response was noted in $6 \%$ of the patients whereas stable disease (from 1-8 months) was achieved in six patients. During treatment, $64 \%$ of patients demonstrated a conversion from unfavorable to favorable circulating tumor cells (CTC) profile [233]. A phase II trial (NCT01228084) evaluated the anti-tumor efficacy, safety, pharmacokinetics, and pharmacodynamics of sulforaphane-rich extracts $(200 \mu$ moles/day during 20 weeks) in 20 patients with biochemically (PSA) recurrent PCa. PSA decline was used as primary endpoint. One patient experienced $\geq 50 \%$ PSA decline, and seven patients had PSA declines less than $50 \%$. No grade 3 events were reported [234]. A double-blinded, randomized, placebocontrolled multicenter trial of sulforaphane-enrolled 78 PCa patients with increasing PSA levels after radical prostatectomy. Sulforaphane was orally administered daily $(60 \mathrm{mg})$ for six months followed by two months without treatment. Patients treated with sulforaphane presented
$86 \%$ longer PSA-DT than the placebo group. Furthermore, changes in PSA levels (increases $>20 \%$ ) were significantly higher in the placebo group $(71.8 \%)$ compared to the sulforaphane-treated group (44.4\%) [235].

Considering these results, HDACi alone did not demonstrate promising results for PCa therapy. Their fast excretion and off-target toxicity allied to their inability to significantly accumulate in solid tumors might be responsible for its lack of efficacy against PCa. Therefore, investigation of new HDACi should be focused on improving tumor cell selectivity and tissue distribution.

\section{Pre-clinical activity of HATi in prostate cancer}

Exposure of PCa cells to curcumin decreased cell proliferation, increased apoptosis and downregulated several important metastasis-promoting genes, including cyclo oxygenase-2 (COX2), Secreted Protein Acidic And Cysteine Rich $(S P A R C)$ and EGF-containing fibulin-like extracellular matrix protein (EFEMP) [236]. This compound also abrogated HGF-mediated increase of vimentin in DU145 cells by downregulating the expression of phosphorylated c-Met, extracellular signal-regulated kinase and Snail, therefore inhibiting EMT [236]. Additionally, it reduced metastasis formation in vivo [237]. Curcumin was also able to demethylate and restore neurogenin 1 ( $\mathrm{Neu}$ rog1) expression and decrease methyl $\mathrm{CpG}$ binding protein 2 (MeCP2) binding to Neurog1 promoter in LNCaP cells [238]. CTK7A targets AR amino-terminal domain leading to its inhibition and to decreased proliferation of androgen-sensitive and castration-resistant AR-positive PCa cells. Moreover, it suppressed tumor growth in a xenograft model of CRPC [239]. Anacardic acid decreased cell proliferation and induced G1/S cell cycle arrest and apoptosis of LNCaP cells. The anti-growth effects of this compound in PCa could be mediated by induction of p53 and p21 protein expression and downregulation of $A R$ [240]. Garcinol inhibited autophagy and colony formation ability, induced apoptosis of human PCa cells, and reduced tumor volume in a xenograft mouse model [241, 242]. Importantly, apoptosis seemed to be mediated by garcinol-mediated downregulation of NF-kB signaling [242]. Likewise, in PCa cell lines, plumbagin decreased cell proliferation and increased mitochondria-mediated apoptosis and autophagy 
through inhibition of PI3K/Akt/mTOR pathway and SIRT1, respectively [243]. These effects were particularly manifest in BRCA1/2-negative CRPC cells. This compound also seems to target PCa stem cells [244]. Furthermore, Embelin was shown to inhibit cell growth, migration, and invasion of $\mathrm{PCa}$ cell lines through modulation of Akt signaling and GSK-3 $\beta$ activation $[245,246]$. This compound potentiated radiotherapy for tumor growth suppression (in vitro and in vivo) and increased the anti-proliferative and the apoptotic effects of anti-androgen therapy leading to AR downregulation $[247,248]$. Accordingly, NK13650A inhibited AR mediated transcriptional activation in both hormone-naive and castration-resistant PCa cells [155]. On the other hand, C646 induced caspase-dependent apoptosis and decreased the migration and invasion capacity of PCa cells [157]. Interestingly, TIP60 which may function as AR co-activator is overexpressed in PCa tissues and significantly correlates with disease progression [249]. NU9056 inhibits TIP60 activity, as well as AR and PSA expression, reducing cell viability and inducing apoptosis via caspases 3 and 9 activation in PCa cell lines. Remarkably, CRPC cell lines were more sensitive to NU9056 than hormonenaive cells [158]. Both NU9056 and TH1834 sensitized PCa cells to radiation therapy $[158,159]$.

Two clinical trials with curcumin are now recruiting PCa patients (NCT02064673 and NCT02095717).

\section{Pre-clinical activity of HMTi and HDMi in prostate cancer}

Exposure of PCa cells to DZNeP resulted in cell cycle arrest in LNCaP and increased apoptosis in DU145 cells and diminished its invasion capacity. Moreover, this compound reduced tumor growth in mice and decreased PCa stem cells self-renewal [250]. GSK126 inhibited either polycomb-dependent or independent activity of EZH2 in PCa cells [251]. EPZ005687 demonstrated dose-dependent inhibition of H3K27me3 in PCa cells [252]. A-366 is a potent G9A and GLP inhibitor which efficiently reduces $\mathrm{H} 3 \mathrm{~K} 9 \mathrm{me} 2$ in $\mathrm{PC}-3$ cells, at micromolar concentrations [253]. CARM1 (PRMT4) inhibitors [1-benzyl-3,5-bis-(3-bromo-4-hydroxybenzylidene)piperidin-4-one and its analogues] significantly reduced PSA promoter activity in LNCaP cells in a dose-dependent fashion [254]. Currently, there are no clinical studies involving HMTi in PCa.

Pargyline decreased demethylation of H3K9 by LSD1, which co-localizes with AR, therefore inhibiting androgen target genes re-expression in $\mathrm{PCa}$ [55]. Furthermore, this LSD1 inhibitor reduced migration and invasion ability and inhibited EMT transition in vitro and in vivo. Suppression of EMT transition was apparent through increased E-cadherin expression, and $\mathrm{N}$-cadherin, and vimentin downregulation. This drug was also able to reduce PSA expression both in vitro and in vivo, delaying CRPC onset [255]. Pargyline and tranylcypromine induced cell cycle arrest at $\mathrm{G} 1$ and increased apoptosis of $\mathrm{LNCaP}$ cells [256]. LNCaP cells and xenograft models treated with namoline, displayed reduced cell viability, and tumor volume. This compound was proposed as a potential therapeutic agent against hormone-sensitive $\mathrm{PCa}$, since it induced silencing of AR-regulated genes [175]. Because LSD1 and JMJD2 are coexpressed and colocalized with AR in PCa cells, there have been efforts to synthetize pandemethylase inhibitors that might simultaneously inhibit LSD1 and ImjC KDMs. Several of these compounds induced apoptosis, arrested cell cycle at G1, and decreased proliferation and migration of LNCaP cells [257].

Finally, two clinical trials will be conducted with the nonspecific MAO inhibitor phenelzine, alone (NCT02217709) or in combination with docetaxel (NCT01253642).

\section{Pre-clinical activity of BET inhibitors in prostate cancer}

I-BET762 decreased PCa cell lines proliferation and reduced tumor burden in an in vivo model of a patientderived tumor and these encouraging results might be due to $M Y C$ downregulation [258]. JQ1 also exhibited anticancer activity in PCa, especially in CRPC cell lines [183]. It was demonstrated that JQ1 acts downstream of AR, disrupting its recruitment to target gene loci. This compound also has the ability to downregulate either the expression or the oncogenic activity of $M Y C$ and transmembrane protease serine 2-v-ets avian erythroblastosis virus E26 oncogene homolog (TMPRSS2-ETS) gene fusion products. I-CBP112 significantly decreased LNCaP cell proliferation through increased H3K18 acetylation [187]. These data suggest that BET bromodomain inhibitors might be therapeutically useful tools in PCa. However, the molecular mechanisms that determine the activity of BET inhibitors upon MYC and AR regulation in PCa must be further investigated. Two clinical trials with the $\mathrm{BET}$ inhibitor OTX015 in solid tumors, including CRPC are ongoing (NCT02698176 and NCT02259114) and might shed some light on the potential clinical usefulness of these compounds.

\section{Combination strategies: epigenetic modulators and conventional therapy \\ Pre-clinical assays}

Co-treatment of DU145 cells with 5-aza-2'-deoxycytidine and sodium butyrate induced site-specific demethylation in the $A R$ promoter region with concomitant gene reexpression [259]. In another pre-clinical assay, combination of 5-azacytidine and docetaxel also induced tumor growth delay. In fact, 5-azacytidine sensitized PC-3 and 22Rv1 xenografts to docetaxel, and this combination was not only well tolerated by mice but it was also superior compared to either agent alone [260]. Combined exposure to 5-aza-2'-deoxycytidine and GSK126 (EZH2 inhibitor) showed an additive inhibitory effect on growth of cancer cells in vitro and re-expression of tumor suppressor genes. 
Moreover, it induced a more powerful in vivo inhibition of PC-3 xenograft tumor growth than 5-aza-2'-deoxycytidine alone [261]. In another study, GSK126 combined with conventional chemotherapy sensitized CRPC cells to apoptosis and growth inhibition both in vitro and in vivo [251]. These results suggest that EZH2 inhibitors might be helpful to increase CRPC patient response to conventional therapy.

PCa cells exposed to vorinostat/SAHA combined with olaparib (a PARP inhibitor) demonstrated a synergistic decrease in cell viability and clonogenicity, as well as an increase in apoptosis and DNA damage compared with single agent, not affecting normal prostate cells [262]. This compound also enhanced radiation-induced apoptosis in DU145 cells [263] and demonstrated a synergistic effect with zoledronic acid, increasing LNCaP and PC-3 cell death [264]. Moreover, low doses of vorinostat/SAHA combined with bicalutamide, synergistically increased apoptosis and decreased cell proliferation [265]. Panobinostat combined with radiotherapy (RT) significantly improved the efficiency of cell death and induced persistent DNA double strand breaks, suggesting that it might increase radiosensitivity of $\mathrm{PCa}$ [266]. Moreover, chemosensitivity to gemcitabine was augmented in DU145 cells and xenografts after pre-treatment with low-dose romidepsin [267]. Romidepsin combined with docetaxel not only demonstrated superior cytotoxic effects in CRPC cell lines but it also significantly reduced tumor growth in mice [268]. A combination of sulforaphane, bicalutamide, and enzalutamide enhanced the anti-proliferative effects, decreased tumor cell migration, and reduced PSA and AR expression in LNCaP and C4-2B cells [269].

Anacardic acid sensitized $\mathrm{PCa}$ cell lines to radiation therapy by decreasing H2AX and p-H2AX expression [270]. Recently, exposure of enzalutamide-resistant mCRPC cells to BETi (JQ1 and OTX015) resulted in attenuation of AR target genes (FKBP5, KLK3,ERG, and $M Y C)$ and $A R-v 7$ expression as well as decreased CRPC cell proliferation in vitro and tumor growth in vivo. Moreover, BETi enhanced the anti-tumor effects of the anti-androgens enzalutamide and ARN509 in a in vivo model [271]. UVI5008, a multitarget epi-drug that inhibits HDACs, Sirtuins, and DNMTs, decreased DU145 cell proliferation, and induced apoptosis by activating initiator and effector caspases and reducing mitochondrial membrane potential [272].

\section{Clinical trials}

A phase I clinical trial (NCT00503984) with 5-azacytidine combined with docetaxel (alternately escalated in a standard $3+3$ design) and prednisone $(5 \mathrm{mg}$ twice daily continuously), in a 21-day cycle, enrolled 15 mCRPC patients, which had progressed during or within six months of chemotherapy with docetaxel. No dose-limiting toxicity was observed, and the most common adverse event related was neutropenia. A phase II clinical trial- enrolled six patients who received $150 \mathrm{mg} / \mathrm{m}^{2}$ of 5 azacytidine for five days followed by $75 \mathrm{mg} / \mathrm{m}^{2}$ of docetaxel on day six during 46 cycles. Grade 3 hematologic and non-hematological toxicities were observed, and one patient died from neutropenic sepsis. Subsequently, 5azacytidine schedule was reduced to $75 \mathrm{mg} / \mathrm{m}^{2}$ daily for five days followed by docetaxel. PSA response was observed in 10 of 19 (52.6\%) patients, and the median duration of response was 20.5 weeks. A complete response was achieved in one patient, partial response in two patients, five patients showed stable disease, and two patients experienced disease progression [273].

In a phase I clinical (NCT00565227) which enrolled four CRPC patients, the combination of vorinostat/SAHA, given orally with intravenous docetaxel induced high toxicity, entailing trial closure [274]. A phase I trial (NCT00331955) combined oral vorinostat/SAHA (administered on days 1, 2 , and 3 with a planned dose escalation of $600 \mathrm{mg}$ given twice a day in two divided doses) and $20 \mathrm{mg} / \mathrm{m}^{2}$ of the topoisomerase II inhibitor doxorubicin (infused on third day, $4 \mathrm{~h}$ after the last vorinostat/SAHA dose). Partial response was achieved in one of the two $\mathrm{PCa}$ patients enrolled [275]. Sixteen CRPC patients were enrolled in a parallel, two-arm, open-label, phase IA/IB study (NCT 00663832), with oral panobinostat alone (20 mg administered on days 1,3 , and 5 for two consecutive weeks) or in combination with docetaxel and prednisone $(15 \mathrm{mg}$ of panobinostat administered in the same schedule and $75 \mathrm{mg} / \mathrm{m}^{2}$ of docetaxel every 21 days). Partial response was achieved in five $(63 \%)$ patients taking the combined therapy whereas none was obtained with panobinostat alone arm. However, patients from both arms showed grade 3 toxicities [276]. A randomized phase I/II trial (NC T00878436) of panobinostat (three different schedules-C1 $60 \mathrm{mg} /$ weeek, C2 $90 \mathrm{mg} /$ week, C3 $120 \mathrm{mg} /$ week, orally) and bicalutamide (50 mg PO daily) was conducted in nine CRPC patients. Grade 3 toxicities were observed and PSA decline $\geq 50 \%$ was observed in two patients and stable PSA in three patients. As this regimen was well tolerated by the patients showing promising PSA responses, the study proceeded for phase II [277]. A phase I clinical trial (NCT00530907) in which VPA (5.3 mg/kg PO daily) was combined with bevacizumab $(11 \mathrm{mg} / \mathrm{kg}$ IV once every 14 days) demonstrated that this combination was safe and well tolerated by the patients. One of the six PCa patients $(17 \%)$ enrolled in this trial presented stable disease for over 6 months [278].

A phase II clinical trial evaluated the combinatory effect of curcumin, prednisone, and docetaxel in 30 CRPC patients. Docetaxel and prednisone were administered in standard conditions for six cycles and curcumin at $6000 \mathrm{mg} /$ day (day -4 to day +2 of docetaxel). This schedule was well tolerated by the patients, with no significant toxicities observed. Decreased PSA levels were observed in $59 \%$ of 
patients, and $40 \%$ of evaluable patients presented a partial response [279]. Another clinical trial (NCT01917890) investigated the efficacy of curcumin and radiotherapy. PCa patients $(n=40)$ undergoing external beam radiotherapy were randomly selected to receive $3 \mathrm{~g}$ /day curcumin orally $(n=20)$ or a placebo $(n=20)$. Patients who received curcumin present reduced urinary symptoms related to radiotherapy, suggesting that this compound could offer radioprotective effects [280].

\section{Conclusion and future directions}

Considering the success of epigenetic drugs in acute leukemia and myelodysplastic syndrome, there is a growing interest for their use in solid tumors. The results of epigenetic-based therapy in cutaneous lymphomas further suggest the possibility that solid tumors may also respond to such treatment.

Concerning DNMT inhibitors, the lack of success of azanucleosides observed in solid tumors, including $\mathrm{PCa}$, might be due to the fact that they are mostly effective in highly proliferative tumors and the rate of active cell division is much lower in solid tumors, compared to hematolymphoid neoplasms. Moreover, the potential of demethylating agents to cause global hypomethylation leading to unwanted activation of imprinted or silenced genes is an additional concern. Therefore, their lack of specificity might paradoxically contribute to tumorigenesis and increased disease aggressiveness due to upregulation of genes involved in metastasis. Indeed, several studies have shown incredible substantial decrease in $\mathrm{m}^{5} \mathrm{C}$ content alongside with specific demethylation of tumor suppressor gene promoters with concomitant re-expression [281]. Treatment with azanucleosides is also associated with hematopoietic, nervous, and metabolic toxicity. However, they usually display a lower toxicity profile than conventional chemotherapy. Although, nonnucleoside inhibitor compounds are less cytotoxic than nucleoside inhibitors, they proved to be less effective than azanucleosides at inhibiting DNA methylation and reactivating gene expression $[69,102,116]$.

Considering histone modulators, the best studied thus far are HDACi. However, these compounds are not specific and they rather act on non-histone proteins in addition to histones, which could contribute to more aggressive side effects. Nevertheless, it was shown that these drugs preferentially target genes that have become abnormally silenced in cancer and, indeed, the chromatin silencing structure induced by cancer is more susceptible to reactivation than the structure of physiologically compacted chromatin [282]. The ideal treatment would be the one that could selectively reverse hypermethylation of tumor suppressor genes' promoters, reestablishing its function, without causing global demethylation of the genome. Eventually, the combination of DNMTi with HDACi and conventional chemotherapy might be a promising strategy for the treatment of $\mathrm{PCa}$ patients. Nevertheless, additional studies are required to assess the role of DNMTi, especially non-nucleoside analogues, as therapeutic options for PCa.

Of some concern, much of the clinical evaluation of epigenetic therapeutics in $\mathrm{PCa}$ to date has been undertaken in late stage, heavily pre-treated mCRPC patients, commonly without a patient stratification strategy and with agents of sometimes poorly defined specificity for epigenetic effect (particularly for "repurposed" drugs). Since epigenetics is a complex process of gene regulation, there is a need for evaluation of agents where we understand clearly the epigenetic target(s), in clinical trials where we also test potential predictive biomarkers to select patients that would benefit from these therapies. Ideally, preclinical studies should focus on providing patient stratification hypotheses that we can take through to the clinic. Earlier stage disease, for example, patients who have biochemical recurrence after radical prostatectomy or patients receiving ADT prior to transition to a CRPC phenotype might represent more relevant clinical settings for assessment of epigenetic therapeutics [28]. It might also be useful to evaluate other parameters. For example, low doses of 5-aza-2'-deoxycytidine have shown to be able to minimize toxicity while potentially improving the targeted effects of DNA hypomethylation [283]. Thus, the hypothesis of reducing dose to an epigenetic but not cytotoxic level might allow us to target better the therapeutic index between efficacy and safety, particularly in combinations of either epigenetic/epigenetic and epigenetic/ non-epigenetic drugs. In addition, we have relatively limited experience of the clinical impact of prolonged maintenance treatment with epigenetic agents, at high or low dose, in terms of toxicity profiles or mechanisms of emergent acquired resistance to therapy. Together with increased insight into the molecular mechanisms underlying the activity of epigenetic-based drugs, linking the rapidly advancing biological understanding of the disease for more precise selection of PCa subtypes for clinical trials will hopefully foster successful clinical validation of these drugs for the treatment of PCa.

\footnotetext{
Abbreviations

ABCB1: ATP binding cassette subfamily B member 1; AdoHcy: S-Adenosyl-Ihomocysteine; AdoMet: S-Adenosyl-methionine; ADT: Androgen deprivation therapy; ALDH1: Aldehyde dehydrogenase 1; ALL: Acute lymphocytic leukemia; AML: Acute myeloid leukemia; APC: Adenomatous polyposis coli; AR: Androgen receptor; BCL2: B cell CLL/lymphoma 2; BET: Bromodomain and extraterminal domain family; BRD: Bromodomain containing; CCND2: Cyclin D2; COX2: Cyclooxygenase-2; CRPC: Castration-resistant prostate cancer; CTC: Circulating tumor cells; DHT: Dihydrotestosterone; DNMT: DNA methyltransferase; DNMTi: DNA methyltransferases inhibitors; DZNeP: 3-Dezaneplanocin-A; EFEMP: EGF-containing fibulin-like extracellular matrix protein; EGCG: Epigallocatechin-3-gallate; EGF: Epidermal growth factor; EGFR: Epidermal growth factor receptor; EMT: Epithelial mesenchymal transition; ERß: Estrogen receptor $\beta$; ETS: v-ets Avian erythroblastosis virus E26 oncogene homolog; EZH2: Enhancer of zeste 2 polycomb repressive complex 2 subunit; FAD: Flavin adenine dinucleotide; FDA: Food and Drug
} 
Administration; GnRH: Gonadotropin-realizing hormone; GSTP1: Glutathione S-transferase pi 1; HAT: Histone acetyltransferase; HATi: Histone acetyltransferase inhibitors; HDAC: Histone deacetylases; HDACi: Histone deacetylase inhibitors; HDM: Histone demethylase; HDMi: Histone demethylase inhibitor; HER2: Human epidermal growth factor receptor 2; HMT: Histone methyltransferase; HMTi: Histone methyltransferase inhibitor; IL-6: Interleukin 6; IGF2: Insulin-like growth factor 2; I.v.: Intravenous; KDM1A: Lysine-specific demethylase 1A; LSD1: Lysine (K)-specific demethylase 1A; MAO: Monoamine oxidase; mCRPC: Metastatic castration-resistant prostate cancer; MeCP2: Methyl CpG binding protein 2; MGMT: 0-6-Methylguanine-DNA methyltransferase; MYC: v-Myc avian myelocytomatosis viral oncogene homolog; NDRG1: N-Myc downstream regulated gene-1; Neurog 1: Neurogenin 1; NF-kB: Nuclear factor kappa B; PCa: Prostate cancer; PFS: Progression-free survival; PIN: Prostatic intraepithelial neoplasia; PLAU: Urokinase plasminogen activator; PRC2: Polycomb repressive complex 2; PSA: Prostate-specific antigen; PTGS2: Prostaglandin-endoperoxide synthase 2; PTMs: Histone post-translational modifications; RARß2: Retinoic acid receptor beta 2; RASSF1A: Ras association domain family protein 1, isoform A; RT: Radiotherapy; SAHA: Suberoylanilide hydroxamic acid; SAM: S-Adenosylmethionine; SIRT: Sirtuin; SPARC: Secreted protein acid and cysteine rich; TMPRSS2: Transmembrane protease serine 2; TSA: Trichostatin A; UTR: Untranslated region; VPA: Valproic acid

\section{Acknowledgements}

The page charges of this publication are supported by COST ACTION CM1406.

The authors are grateful to Mrs. Manuela Montezuma for her drawing on Fig. 3.

\section{Funding}

IG is a research fellow from Federal funds through Programa Operacional Temático Factores de Competitividade (COMPETE) with co-participation from the European Community Fund (FEDER) and by national funds through Fundação para a Ciência e Tecnologia (CI-IPOP-BPD/UID/DTP/00776/2013). CJ's research is supported by Research Center of the Portuguese Oncology Institute of Porto. SJC's and GP's research on epigenetics is supported by Cancer Research UK and the Experimental Cancer Medicine Centre.

\section{Availability of data and materials}

\section{Not applicable.}

\section{Authors' contributions}

IG, EP-S, and SJC collected the information. IG, EP-S, RH, GP, SJC, and CJ wrote and revised the paper. IG and EP-S draw the Figs. 1 and 2. All authors read and approved the final manuscript.

\section{Competing interests}

The authors declare that they have no competing interests.

\section{Consent for publication}

Not applicable.

\section{Ethics approval and consent to participate}

Not applicable.

\begin{abstract}
Author details
${ }^{1}$ Cancer Biology and Epigenetics Group-Research Center (CI-IPOP), Portuguese Oncology Institute of Porto (IPO-Porto), Research Center-LAB 3, F Bdg, 1st floor, Rua Dr. António Bernardino de Almeida, 4200-072 Porto, Portugal. ${ }^{2}$ School of Allied Health Sciences (ESTSP), Polytechnic of Porto, Porto, Portugal. ${ }^{3}$ Department of Pathology, Portuguese Oncology Institute of Porto (IPO Porto), Rua Dr. António Bernardino de Almeida, 4200-072 Porto, Portugal. ${ }^{4}$ Department of Pathology and Molecular Immunology, Institute of Biomedical Sciences Abel Salazar-University of Porto (ICBAS-UP), Porto, Portugal. ${ }^{5}$ Cancer Research UK Centre, Cancer Sciences, The Somers Cancer Research Building, University of Southampton Faculty of Medicine, Southampton General Hospital, Southampton S016 6YD, UK.
\end{abstract}

Received: 7 July 2016 Accepted: 7 September 2016 Published online: 15 September 2016

\section{References}

1. Torre LA, Bray F, Siegel RL, Ferlay J, Lortet-Tieulent J, Jemal A. Global cancer statistics, 2012. CA Cancer J Clin. 2015;65(2):87-108.

2. Kohli M, Tindall DJ. New developments in the medical management of prostate cancer. Mayo Clin Proc. 2010;85(1):77-86.

3. Perlmutter MA, Lepor $\mathrm{H}$. Androgen deprivation therapy in the treatment of advanced prostate cancer. Rev Urol. 2007;9 Suppl 1:S3-8.

4. James ND, Sydes MR, Clarke NW, Mason MD, Dearnaley DP, Spears MR, et al. Addition of docetaxel, zoledronic acid, or both to first-line long-term hormone therapy in prostate cancer (STAMPEDE): survival results from an adaptive, multiarm, multistage, platform randomised controlled trial. Lancet. 2016;387(10024):1163-77.

5. Sweeney CJ, Chen YH, Carducci M, Liu G, Jarrard DF, Eisenberger M, et al. Chemohormonal therapy in metastatic hormone-sensitive prostate cancer. N Engl J Med. 2015;373(8):737-46.

6. Heidenreich A, Bastian PJ, Bellmunt J, Bolla M, Joniau S, van der Kwast T, et al. EAU guidelines on prostate cancer. Part II: treatment of advanced, relapsing, and castration-resistant prostate cancer. Eur Urol. 2014;65(2):467-79.

7. James ND, Spears MR, Clarke NW, Dearnaley DP, De Bono JS, Gale J, et al. Survival with newly diagnosed metastatic prostate cancer in the "Docetaxel Era": data from 917 patients in the control arm of the STAMPEDE trial (MRC PR08, CRUK/06/019). Eur Urol. 2015;67(6):1028-38.

8. Watson PA, Arora VK, Sawyers CL. Emerging mechanisms of resistance to androgen receptor inhibitors in prostate cancer. Nat Rev Cancer. 2015;15(12):701-11.

9. Shafi AA, Yen AE, Weigel NL. Androgen receptors in hormone-dependent and castration-resistant prostate cancer. Pharmacol Ther. 2013;140(3):223-38.

10. Claessens F, Helsen C, Prekovic S, Van den Broeck T, Spans L, Van Poppel H, et al. Emerging mechanisms of enzalutamide resistance in prostate cancer. Nat Rev Urol. 2014;11(12):712-6.

11. Ryan CJ, Smith MR, de Bono JS, Molina A, Logothetis CJ, de Souza P, et al. Abiraterone in metastatic prostate cancer without previous chemotherapy. N Engl J Med. 2013;368(2):138-48.

12. Beer TM, Armstrong AJ, Rathkopf DE, Loriot $Y$, Sternberg CN, Higano CS, et al. Enzalutamide in metastatic prostate cancer before chemotherapy. N Engl J Med. 2014;371(5):424-33.

13. Antonarakis ES, Lu C, Wang H, Luber B, Nakazawa M, Roeser JC, et al. AR-V7 and resistance to enzalutamide and abiraterone in prostate cancer. N Engl J Med. 2014;371(11):1028-38.

14. Gundem G, Van Loo P, Kremeyer B, Alexandrov LB, Tubio JM, Papaemmanuil $\mathrm{E}$, et al. The evolutionary history of lethal metastatic prostate cancer. Nature. 2015;520(7547):353-7.

15. Berthold DR, Pond GR, Soban F, de Wit R, Eisenberger M, Tannock IF. Docetaxel plus prednisone or mitoxantrone plus prednisone for advanced prostate cancer: updated survival in the TAX 327 study. J Clin Oncol. 2008;26(2):242-5.

16. de Bono JS, Oudard S, Ozguroglu M, Hansen S, Machiels JP, Kocak I, et al. Prednisone plus cabazitaxel or mitoxantrone for metastatic castration-resistant prostate cancer progressing after docetaxel treatment: a randomised open-label trial. Lancet. 2010;376(9747):1147-54.

17. Kantoff PW, Higano CS, Shore ND, Berger ER, Small EJ, Penson DF, et al. Sipuleucel-T immunotherapy for castration-resistant prostate cancer. N Engl J Med. 2010;363(5):411-22.

18. Maluf FC, Smaletz O, Herchenhorn D. Castration-resistant prostate cancer: systemic therapy in 2012. Clinics (Sao Paulo). 2012;67(4):389-94.

19. Parker C, Nilsson S, Heinrich D, Helle SI, O'Sullivan JM, Fossa SD, et al. Alpha emitter radium-223 and survival in metastatic prostate cancer. N Engl J Med. 2013;369(3):213-23.

20. Boyd LK, Mao X, Lu Y-J. The complexity of prostate cancer: genomic alterations and heterogeneity. Nat Rev Urol. 2012;9(11):652-64.

21. Jeronimo C, Bastian PJ, Bjartell A, Carbone GM, Catto JW, Clark SJ, et al. Epigenetics in prostate cancer: biologic and clinical relevance. Eur Urol. 2011;60(4):753-66.

22. Jurkowska RZ, Jurkowski TP, Jeltsch A. Structure and function of mammalian DNA methyltransferases. Chembiochem. 2011;12(2):206-22.

23. Okano M, Xie S, Li E. Cloning and characterization of a family of novel mammalian DNA (cytosine-5) methyltransferases. Nat Genet. 1998;19(3):219-20.

24. Yegnasubramanian S, Haffner MC, Zhang Y, Gurel B, Cornish TC, Wu Z, et al DNA hypomethylation arises later in prostate cancer progression than CpG island hypermethylation and contributes to metastatic tumor heterogeneity. Cancer Res. 2008;68(21):8954-67. 
25. Jarrard DF, Bussemakers MJ, Bova GS, Isaacs WB. Regional loss of imprinting of the insulin-like growth factor II gene occurs in human prostate tissues. Clin Cancer Res. 1995;1(12):1471-8.

26. Pakneshan $\mathrm{P}$, Xing $\mathrm{RH}$, Rabbani $\mathrm{SA}$. Methylation status of uPA promoter as a molecular mechanism regulating prostate cancer invasion and growth in vitro and in vivo. FASEB J. 2003;17(9):1081-8.

27. Ogishima T, Shiina H, Breault JE, Tabatabai L, Bassett WW, Enokida H, et al. Increased heparanase expression is caused by promoter hypomethylation and up-regulation of transcriptional factor early growth response- 1 in human prostate cancer. Clin Cancer Res. 2005;11(3):1028-36.

28. Perry AS, Watson RW, Lawler M, Hollywood D. The epigenome as a therapeutic target in prostate cancer. Nat Rev Urol. 2010;7(12):668-80

29. Jeronimo C, Usadel H, Henrique R, Oliveira J, Lopes C, Nelson WG, et al. Quantitation of GSTP1 methylation in non-neoplastic prostatic tissue and organ-confined prostate adenocarcinoma. J Natl Cancer Inst. 2001;93(22):1747-52

30. Henrique R, Jeronimo C. Molecular detection of prostate cancer: a role for GSTP1 hypermethylation. Eur Urol. 2004;46(5):660-9. discussion 9.

31. Millar DS, Ow KK, Paul CL, Russell PJ, Molloy PL, Clark SJ. Detailed methylation analysis of the glutathione S-transferase pi (GSTP1) gene in prostate cancer. Oncogene. 1999;18(6):1313-24.

32. Nakayama M, Bennett CJ, Hicks JL, Epstein Jl, Platz EA, Nelson WG, et al. Hypermethylation of the human glutathione S-transferase-pi gene (GSTP1) CpG island is present in a subset of proliferative inflammatory atrophy lesions but not in normal or hyperplastic epithelium of the prostate: a detailed study using laser-capture microdissection. Am J Pathol. 2003;163(3):923-33.

33. Liu L, Yoon JH, Dammann R, Pfeifer GP. Frequent hypermethylation of the RASSF1A gene in prostate cancer. Oncogene. 2002;21(44):6835-40.

34. Jeronimo C, Henrique R, Hoque MO, Mambo E, Ribeiro FR, Varzim G, et al. A quantitative promoter methylation profile of prostate cancer. Clin Cancer Res. 2004;10(24):8472-8.

35. Schayek H, Bentov I, Sun S, Plymate SR, Werner H. Progression to metastatic stage in a cellular model of prostate cancer is associated with methylation of the androgen receptor gene and transcriptional suppression of the insulin-like growth factor-I receptor gene. Exp Cell Res. 2010;316(9):1479-88.

36. Suzuki $H$, Ueda $T$, Ichikawa $T$, Ito $H$. Androgen receptor involvement in the progression of prostate cancer. Endocr Relat Cancer. 2003;10(2):209-16.

37. Kang GH, Lee S, Lee HJ, Hwang KS. Aberrant CpG island hypermethylation of multiple genes in prostate cancer and prostatic intraepithelial neoplasia. J Pathol. 2004;202(2):233-40.

38. Florl AR, Steinhoff C, Muller M, Seifert HH, Hader C, Engers R, et al. Coordinate hypermethylation at specific genes in prostate carcinoma precedes LINE-1 hypomethylation. Br J Cancer. 2004;91(5):985-94.

39. Henrique R, Jeronimo C, Teixeira MR, Hoque MO, Carvalho AL, Pais I, et al. Epigenetic heterogeneity of high-grade prostatic intraepithelial neoplasia: clues for clonal progression in prostate carcinogenesis. Mol Cancer Res. 2006;4(1):1-8.

40. Kouzarides T. Chromatin modifications and their function. Cell. 2007;128(4):693-705

41. Fullgrabe J, Kavanagh E, Joseph B. Histone onco-modifications. Oncogene. 2011;30(31):3391-403.

42. Halkidou K, Gaughan L, Cook S, Leung HY, Neal DE, Robson CN. Upregulation and nuclear recruitment of HDAC1 in hormone refractory prostate cancer. Prostate. 2004;59(2):177-89.

43. Weichert W, Roske A, Gekeler V, Beckers T, Stephan C, Jung K, et al. Histone deacetylases 1, 2 and 3 are highly expressed in prostate cancer and HDAC2 expression is associated with shorter PSA relapse time after radical prostatectomy. Br J Cancer. 2008;98(3):604-10.

44. Novotny-Diermayr V, Sangthongpitag K, Hu CY, Wu X, Sausgruber N, Yeo P, et al. SB939, a novel potent and orally active histone deacetylase inhibitor with high tumor exposure and efficacy in mouse models of colorectal cancer. Mol Cancer Ther. 2010;9(3):642-52.

45. Korkmaz CG, Fronsdal K, Zhang Y, Lorenzo PI, Saatcioglu F. Potentiation of androgen receptor transcriptional activity by inhibition of histone deacetylation-rescue of transcriptionally compromised mutants. J Endocrinol. 2004;182(3):377-89.

46. Baptista T, Graca I, Sousa EJ, Oliveira Al, Costa NR, Costa-Pinheiro P, et al. Regulation of histone H2A.Z expression is mediated by sirtuin 1 in prostate cancer. Oncotarget. 2013;4(10):1673-85.
47. Hamamoto R, Nakamura Y. Dysregulation of protein methyltransferases in human cancer: an emerging target class for anticancer therapy. Cancer Sci. 2016. doi:10.1111/cas.12884.

48. Ellinger J, Kahl P, von der Gathen J, Rogenhofer S, Heukamp LC, Gutgemann I, et al. Global levels of histone modifications predict prostate cancer recurrence. Prostate. 2010;70(1):61-9.

49. Kahl P, Gullotti L, Heukamp LC, Wolf S, Friedrichs N, Vorreuther R, et al. Androgen receptor coactivators lysine-specific histone demethylase 1 and four and a half LIM domain protein 2 predict risk of prostate cancer recurrence. Cancer Res. 2006;66(23):11341-7.

50. Wissmann M, Yin N, Muller JM, Greschik H, Fodor BD, Jenuwein T, et al. Cooperative demethylation by JMJD2C and LSD1 promotes androgen receptor-dependent gene expression. Nat Cell Biol. 2007;9(3):347-53.

51. Varambally S, Dhanasekaran SM, Zhou M, Barrette TR, Kumar-Sinha C, Sanda $M G$, et al. The polycomb group protein $E Z H 2$ is involved in progression of prostate cancer. Nature. 2002;419(6907):624-9.

52. Yu J, Rhodes DR, Tomlins SA, Cao X, Chen G, Mehra R, et al. A polycomb repression signature in metastatic prostate cancer predicts cancer outcome. Cancer Res. 2007;67(22):10657-63.

53. Xu K, Wu ZJ, Groner AC, He HH, Cai C, Lis RT, et al. EZH2 oncogenic activity in castration-resistant prostate cancer cells is polycomb-independent. Science. 2012;338(6113):1465-9.

54. Opel M, Lando D, Bonilla C, Trewick SC, Boukaba A, Walfridsson J, et al. Genome-wide studies of histone demethylation catalysed by the fission yeast homologues of mammalian LSD1. PLoS One. 2007;2(4):e386.

55. Metzger E, Wissmann M, Yin N, Muller JM, Schneider R, Peters AH, et al. LSD1 demethylates repressive histone marks to promote androgenreceptor-dependent transcription. Nature. 2005:437(7057):436-9.

56. Gaughan L, Stockley J, Wang N, McCracken SR, Treumann A, Armstrong K, et al. Regulation of the androgen receptor by SET9-mediated methylation. Nucleic Acids Res. 2010. doi:10.1093/nar/gkq861

57. Suikki HE, Kujala PM, Tammela TL, van Weerden WM, Vessella RL, Visakorpi T. Genetic alterations and changes in expression of histone demethylases in prostate cancer. Prostate. 2010;70(8):889-98.

58. Vieira FQ, Costa-Pinheiro P, Almeida-Rios D, Graça I, Monteiro-Reis S, Simões-Sousa $\mathrm{S}$, et al. SMYD3 contributes to a more aggressive phenotype of prostate cancer and targets cyclin D2 through H4K20me3. Oncotarget. 2015;6(15):13644.

59. Vieira FQ, Costa-Pinheiro P, Ramalho-Carvalho J, Pereira A, Menezes FD, Antunes $L$, et al. Deregulated expression of selected histone methylases and demethylases in prostate carcinoma. Endocr Relat Cancer. 2014;21(1):51-61.

60. Bianco-Miotto T, Chiam K, Buchanan G, Jindal S, Day TK, Thomas M, et al. Global levels of specific histone modifications and an epigenetic gene signature predict prostate cancer progression and development. Cancer Epidemiol Biomarkers Prev. 2010;19(10):2611-22.

61. Yen C-Y, Huang H-W, Shu C-W, Hou M-F, Yuan S-SF, Wang H-R, et al. DNA methylation, histone acetylation and methylation of epigenetic modifications as a therapeutic approach for cancers. Cancer Lett. 2016;373(2):185-92.

62. Fenaux P, Mufti GJ, Hellstrom-Lindberg E, Santini V, Finelli C, Giagounidis A, et al. Efficacy of azacitidine compared with that of conventional care regimens in the treatment of higher-risk myelodysplastic syndromes: a randomised, open-label, phase III study. Lancet Oncol. 2009;10(3):223-32.

63. Kaminskas E, Farrell A, Abraham S, Baird A, Hsieh L-S, Lee S-L, et al. Approval summary: azacitidine for treatment of myelodysplastic syndrome subtypes. Clin Cancer Res. 2005;11(10):3604-8.

64. Kantarjian H, Issa JPJ, Rosenfeld CS, Bennett JM, Albitar M, DiPersio J, et al. Decitabine improves patient outcomes in myelodysplastic syndromes. Cancer. 2006;106(8):1794-803.

65. Mann BS, Johnson JR, Cohen MH, Justice R, Pazdur R. FDA approval summary: vorinostat for treatment of advanced primary cutaneous T-cell lymphoma. Oncologist. 2007;12(10):1247-52.

66. VanderMolen KM, McCulloch W, Pearce CJ, Oberlies NH. Romidepsin (Istodax, NSC 630176, FR901228, FK228, depsipeptide): a natural product recently approved for cutaneous T-cell lymphoma. J Antibiot. 2011;64(8): 525-31.

67. Poole RM. Belinostat: first global approval. Drugs. 2014;74(13):1543-54

68. Richardson PG, Laubach JP, Lonial S, Moreau P, Yoon S-S, Hungria VT, et al. Panobinostat: a novel pan-deacetylase inhibitor for the treatment of relapsed or relapsed and refractory multiple myeloma. Expert Rev Anticancer Ther. 2015;15(7):737-48. 
69. Brueckner B, Kuck D, Lyko F. DNA methyltransferase inhibitors for cancer therapy. Cancer J. 2007;13(1):17-22.

70. Erdmann A, Halby L, Fahy J, Arimondo PB. Targeting DNA methylation with small molecules: what's next? Miniperspective. J Med Chem. 2014;58(6):2569-83.

71. Goffin J, Eisenhauer E. DNA methyltransferase inhibitors — state of the art. Ann Oncol. 2002;13(11):1699-716.

72. Nervi C, De Marinis E, Codacci-Pisanelli G. Epigenetic treatment of solid tumours: a review of clinical trials. Clin Epigenetics. 2015;7:127.

73. Foulks JM, Parnell KM, Nix RN, Chau S, Swierczek K, Saunders M, et al. Epigenetic drug discovery: targeting DNA methyltransferases. J Biomol Screen. 2012;17(1):2-17.

74. Cheng JC, Matsen CB, Gonzales FA, Ye W, Greer S, Marquez VE, et al. Inhibition of DNA methylation and reactivation of silenced genes by zebularine. J Natl Cancer Inst. 2003;95(5):399-409.

75. Barchi JJ, Cooney DA, Weinberg ZHM, Taft C, Marquez VE, Ford H. Improved synthesis of zebularine [1-( $\beta$-D-ribofuranosyl)-dihydropyrimidin-2-one] nucleotides as inhibitors of human deoxycytidylate deaminase. J Enzyme Inhib Med Chem. 1995;9(2):147-62.

76. Nakamura K, Nakabayashi K, Aung KH, Aizawa K, Hori N, Yamauchi J, et al. DNA methyltransferase inhibitor zebularine induces human cholangiocarcinoma cell death through alteration of DNA methylation status. PLoS One. 2015;10(3):e0120545.

77. Napso T, Fares F. Zebularine induces prolonged apoptosis effects via the caspase-3/PARP pathway in head and neck cancer cells. Int J Oncol. 2014;44(6):1971-9.

78. You BR, Park WH. Zebularine inhibits the growth of A549 lung cancer cells via cell cycle arrest and apoptosis. Mol Carcinog. 2014;53(11):847-57.

79. Brueckner B, Rius M, Markelova MR, Fichtner I, Hals P-A, Sandvold ML, et al. Delivery of 5-azacytidine to human cancer cells by elaidic acid esterification increases therapeutic drug efficacy. Mol Cancer Ther. 2010;9(5):1256-64.

80. Hummel-Eisenbeiss J, Hascher A, Hals P-A, Sandvold ML, Müller-Tidow C, Lyko $F$, et al. The role of human equilibrative nucleoside transporter 1 on the cellular transport of the DNA methyltransferase inhibitors 5-azacytidine and CP-4200 in human leukemia cells. Mol Pharmacol. 2013;84(3):438-50.

81. Chuang JC, Warner SL, Vollmer D, Vankayalapati H, Redkar S, Bearss DJ, et al. S110, a 5-aza-2'-deoxycytidine-containing dinucleotide, is an effective DNA methylation inhibitor in vivo and can reduce tumor growth. Mol Cancer Ther. 2010;9(5):1443-50.

82. Srivastava P, Paluch BE, Matsuzaki J, James SR, Collamat-Lai G, Taverna P, et al. Immunomodulatory action of the DNA methyltransferase inhibitor SGI-110 in epithelial ovarian cancer cells and xenografts. Epigenetics. 2015;10(3):237-46.

83. Issa J-PJ, Roboz G, Rizzieri D, Jabbour E, Stock W, O'Connell C, et al. Safety and tolerability of guadecitabine (SGI-110) in patients with myelodysplastic syndrome and acute myeloid leukaemia: a multicentre, randomised, dose-escalation phase 1 study. Lancet Oncol. 2015;16(9):1099-110.

84. Azad N, Zahnow CA, Rudin CM, Baylin SB. The future of epigenetic therapy in solid tumours-lessons from the past. Nat Rev Clin Oncol. 2013;10(5):256-66.

85. Arce C, Segura-Pacheco B, Perez-Cardenas E, Taja-Chayeb L, Candelaria M, Duennas-Gonzalez A. Hydralazine target: from blood vessels to the epigenome. J Transl Med. 2006;4:10

86. Cornacchia E, Golbus J, Maybaum J, Strahler J, Hanash S, Richardson B. Hydralazine and procainamide inhibit T cell DNA methylation and induce autoreactivity. J Immunol. 1988:140(7):2197-200.

87. Deng C, Lu Q, Zhang Z, Rao T, Attwood J, Yung R, et al. Hydralazine may induce autoimmunity by inhibiting extracellular signal-regulated kinase pathway signaling. Arthritis Rheum. 2003;48(3):746-56.

88. Chavez-Blanco A, Perez-Plasencia C, Perez-Cardenas E, Carrasco-Legleu C, Rangel-Lopez E, Segura-Pacheco B, et al. Antineoplastic effects of the DNA methylation inhibitor hydralazine and the histone deacetylase inhibitor valproic acid in cancer cell lines. Cancer Cell Int. 2006;6:2.

89. Segura-Pacheco B, Trejo-Becerril C, Perez-Cardenas E, Taja-Chayeb L, Mariscal I, Chavez A, et al. Reactivation of tumor suppressor genes by the cardiovascular drugs hydralazine and procainamide and their potential use in cancer therapy. Clin Cancer Res. 2003;9(5):1596-603.

90. Song $Y$, Zhang C. Hydralazine inhibits human cervical cancer cell growth in vitro in association with APC demethylation and re-expression. Cancer Chemother Pharmacol. 2009;63(4):605-13.

91. Candelaria M, Gallardo-Rincon D, Arce C, Cetina L, Aquilar-Ponce JL, Arrieta $\mathrm{O}$, et al. A phase II study of epigenetic therapy with hydralazine and magnesium valproate to overcome chemotherapy resistance in refractory solid tumors. Ann Oncol. 2007;18(9):1529-38.

92. Coronel J, Cetina L, Pacheco I, Trejo-Becerril C, Gonzalez-Fierro A, de la Cruz-Hernandez E, et al. A double-blind, placebo-controlled, randomized phase III trial of chemotherapy plus epigenetic therapy with hydralazine valproate for advanced cervical cancer. Preliminary results. Med Oncol. 2011;28 Suppl 1:S540-6.

93. Bauman J, Shaheen M, Verschraegen CF, Belinsky SA, Fekrazad MH, Lee F-C, et al. A phase I protocol of hydralazine and valproic acid in advanced, previously treated solid cancers. Transl Oncol. 2014;7(3):349-54.

94. Lee BH, Yegnasubramanian S, Lin X, Nelson WG. Procainamide is a specific inhibitor of DNA methyltransferase 1. J Biol Chem. 2005;280(49):40749-56.

95. Villar-Garea A, Fraga MF, Espada J, Esteller M. Procaine is a DNA-demethylating agent with growth-inhibitory effects in human cancer cells. Cancer Res. 2003;63(16):4984-9.

96. Lin X, Asgari K, Putzi MJ, Gage WR, Yu X, Cornblatt BS, et al. Reversal of GSTP1 CpG island hypermethylation and reactivation of $\pi$-class glutathione S-transferase (GSTP1) expression in human prostate cancer cells by treatment with procainamide. Cancer Res. 2001;61(24):8611-6.

97. Kuck D, Caulfield T, Lyko F, Medina-Franco JL. Nanaomycin A selectively inhibits DNMT3B and reactivates silenced tumor suppressor genes in human cancer cells. Mol Cancer Ther. 2010;9(11):3015-23.

98. Iljin K, Ketola K, Vainio P, Halonen P, Kohonen P, Fey V, et al. Highthroughput cell-based screening of 4910 known drugs and drug-like small molecules identifies disulfiram as an inhibitor of prostate cancer cell growth. Clin Cancer Res. 2009;15(19):6070-8.

99. Lin J, Haffner MC, Zhang Y, Lee BH, Brennen WN, Britton J, et al. Disulfiram is a DNA demethylating agent and inhibits prostate cancer cell growth. Prostate. 2011;71(4):333-43.

100. Datta J, Ghoshal K, Denny WA, Gamage SA, Brooke DG, Phiasivongsa P, et al. A new class of quinoline-based DNA hypomethylating agents reactivates tumor suppressor genes by blocking DNA methyltransferase 1 activity and inducing its degradation. Cancer Res. 2009;69(10):4277-85.

101. Brueckner B, Boy RG, Siedlecki P, Musch T, Kliem HC, Zielenkiewicz P, et al. Epigenetic reactivation of tumor suppressor genes by a novel small-molecule inhibitor of human DNA methyltransferases. Cancer Res. 2005;65(14):6305-11.

102. Stresemann C, Brueckner B, Musch T, Stopper H, Lyko F. Functional diversity of DNA methyltransferase inhibitors in human cancer cell lines. Cancer Res. 2006;66(5):2794-800

103. Schirrmacher E, Beck C, Brueckner B, Schmitges F, Siedlecki P, Bartenstein P, et al. Synthesis and in vitro evaluation of biotinylated RG108: a high affinity compound for studying binding interactions with human DNA methyltransferases. Bioconjug Chem. 2006;17(2):261-6.

104. Savickiene J, Treigyte G, Borutinskaite W, Navakauskiene R. Antileukemic activity of combined epigenetic agents, DNMT inhibitors zebularine and RG108 with HDAC inhibitors, against promyelocytic leukemia HL-60 cells. Cell Mol Biol Lett. 2012;17(4):501-25.

105. Savickiene J, Treigyte G, Jazdauskaite A, Borutinskaite W, Navakauskiene R. DNA methyltransferase inhibitor RG108 and histone deacetylase inhibitors cooperate to enhance NB4 cell differentiation and E-cadherin re-expression by chromatin remodelling. Cell Biol Int. 2012;36(11):1067-78.

106. Amato RJ. Inhibition of DNA methylation by antisense oligonucleotide MG98 as cancer therapy. Clin Genitourin Cancer. 2007;5(7):422-6.

107. Winquist E, Knox J, Ayoub J-P, Wood L, Wainman N, Reid GK, et al. Phase II trial of DNA methyltransferase 1 inhibition with the antisense oligonucleotide MG98 in patients with metastatic renal carcinoma: a National Cancer Institute of Canada Clinical Trials Group investigational new drug study. Investig New Drugs. 2006;24(2):159-67.

108. Klisovic RB, Stock W, Cataland S, Klisovic MI, Liu S, Blum W, et al. A phase I biological study of MG98, an oligodeoxynucleotide antisense to DNA methyltransferase 1 , in patients with high-risk myelodysplasia and acute myeloid leukemia. Clin Cancer Res. 2008;14(8):2444-9.

109. Plummer R, Vidal L, Griffin M, Lesley M, de Bono J, Coulthard S, et al. Phase I study of MG98, an oligonucleotide antisense inhibitor of human DNA methyltransferase 1, given as a 7-day infusion in patients with advanced solid tumors. Clin Cancer Res. 2009;15(9):3177-83.

110. Pudenz M, Roth K, Gerhauser C. Impact of soy isoflavones on the epigenome in cancer prevention. Nutrients. 2014;6(10):4218-72.

111. Lee WJ, Shim J-Y, Zhu BT. Mechanisms for the inhibition of DNA methyltransferases by tea catechins and bioflavonoids. Mol Pharmacol. 2005;68(4):1018-30. 
112. Gravina GL, Festuccia C, Millimaggi D, Dolo V, Tombolini V, de Vito M, et al. Chronic azacitidine treatment results in differentiating effects, sensitizes against bicalutamide in androgen-independent prostate cancer cells. Prostate. 2008;68(7):793-801.

113. Gravina GL, Marampon F, Di Staso M, Bonfili P, Vitturini A, Jannini EA, et al. 5-Azacitidine restores and amplifies the bicalutamide response on preclinical models of androgen receptor expressing or deficient prostate tumors. Prostate. 2010;70(11):1166-78.

114. Tian J, Lee SO, Liang L, Luo J, Huang C-K, Li L, et al. Targeting the unique methylation pattern of androgen receptor (AR) promoter in prostate stem/progenitor cells with 5-aza-2'-deoxycytidine (5-AZA) leads to suppressed prostate tumorigenesis. J Biol Chem. 2012;287(47):39954-66.

115. Sabatino MA, Geroni C, Ganzinelli M, Ceruti R, Broggini M. Zebularine partially reverses GST methylation in prostate cancer cells and restores sensitivity to the DNA minor groove binder brostallicin. Epigenetics. 2013;8(6):656-65.

116. Chuang JC, Yoo CB, Kwan JM, Li TW, Liang G, Yang AS, et al. Comparison of biological effects of non-nucleoside DNA methylation inhibitors versus 5-aza-2'-deoxycytidine. Mol Cancer Ther. 2005;4(10):1515-20.

117. Halby L, Champion C, Sénamaud-Beaufort C, Ajjan S, Drujon T, Rajavelu A, et al. Rapid synthesis of new DNMT inhibitors derivatives of procainamide. Chembiochem. 2012;13(1):157-65.

118. Graca I, Sousa E, Baptista T, Almeida M, Ramalho-Carvalho J, Palmeira C, et al. Anti-tumoral effect of the non-nucleoside DNMT inhibitor RG108 in human prostate cancer cells. Curr Pharm Des. 2013;20:1803-11.

119. Graça I, Sousa EJ, Costa-Pinheiro P, Vieira FQ, Torres-Ferreira J, Martins MG, et al. Anti-neoplastic properties of hydralazine in prostate cancer. Oncotarget. 2014;5:5950-64.

120. Valente S, Liu Y, Schnekenburger M, Zwergel C, Cosconati S, Gros C, et al. Selective non-nucleoside inhibitors of human DNA methyltransferases active in cancer including in cancer stem cells. J Med Chem. 2014;57(3):701-13.

121. Jagadeesh S, Sinha S, Pal BC, Bhattacharya S, Banerjee PP. Mahanine reverses an epigenetically silenced tumor suppressor gene RASSF1A in human prostate cancer cells. Biochem Biophys Res Commun. 2007;362(1):212-7.

122. Sinha S, Pal BC, Jagadeesh S, Banerjee PP, Bandyopadhaya A, Bhattacharya S. Mahanine inhibits growth and induces apoptosis in prostate cancer cells through the deactivation of Akt and activation of caspases. Prostate. 2006;66(12):1257-65

123. Ceccaldi A, Rajavelu A, Ragozin S, Sénamaud-Beaufort C, Bashtrykov P, Testa $\mathrm{N}$, et al. Identification of novel inhibitors of DNA methylation by screening of a chemical library. ACS Chem Biol. 2013;8(3):543-8.

124. Fang MZ, Chen D, Sun Y, Jin Z, Christman JK, Yang CS. Reversal of hypermethylation and reactivation of p16INK4a, RARß, and MGMT genes by genistein and other isoflavones from soy. Clin Cancer Res. 2005;11(19):7033-41.

125. Vardi A, Bosviel R, Rabiau N, Adjakly M, Satih S, Dechelotte P, et al. Soy phytoestrogens modify DNA methylation of GSTP1, RASSF1A, EPH2 and BRCA1 promoter in prostate cancer cells. In Vivo. 2010;24(4):393-400.

126. Mahmoud AM, Al-alem U, Ali MM, Bosland MC. Genistein increases estrogen receptor beta expression in prostate cancer via reducing its promoter methylation. J Steroid Biochem Mol Biol. 2015;152:62-75.

127. Lee AH, Fraser ML, Meng X, Binns CW. Protective effects of green tea against prostate cancer. Expert Rev Anticancer Ther. 2006;6(4):507-13.

128. Fang MZ, Wang Y, Ai N, Hou Z, Sun Y, Lu H, et al. Tea polyphenol (-)-epigallocatechin-3-gallate inhibits DNA methyltransferase and reactivates methylation-silenced genes in cancer cell lines. Cancer Res. 2003;63(22):7563-70

129. Sharma V, Verma V, Lal N, Yadav SK, Sarkar S, Mandalapu D, et al. Disulfiram and its novel derivative sensitize prostate cancer cells to the growth regulatory mechanisms of the cell by re-expressing the epigenetically repressed tumor suppressor - estrogen receptor $\beta$. Mol Carcinog. 2015. doi: 10.1002/mc.22433.

130. Sonpavde G, Aparicio AM, Zhan F, North B, Delaune R, Garbo LE, Rousey SR, Weinstein RE, Xiao L, Boehm KA, Asmar L, Fleming MT, Galsky MD, Berry WR, Von Hoff DD. Azacitidine favorably modulates PSA kinetics correlating with plasma DNA LINE-1 hypomethylation in men with chemonaïve castration-resistant prostate cancer. Urol Oncol. 2011;29(6):682-9. doi:10.1016/j.urolonc.2009.09.015.

131. Thibault A, Figg WD, Bergan RC, Lush RM, Myers CE, Tompkins A, et al. A phase II study of 5-aza-2'deoxycytidine (decitabine) in hormone independent metastatic (D2) prostate cancer. Tumori. 1998;84(1):87-9.

132. Rodriguez-Paredes M, Esteller M. Cancer epigenetics reaches mainstream oncology. Nat Med. 2011;17(3):330-9.
133. Roche J, Bertrand P. Inside HDACs with more selective HDAC inhibitors. Eur J Med Chem. 2016;121:451-83.

134. Marks PA, Xu WS. Histone deacetylase inhibitors: potential in cancer therapy J Cell Biochem. 2009;107(4):600-8.

135. Lakshmaiah K, Jacob LA, Aparna S, Lokanatha D, Saldanha SC. Epigenetic therapy of cancer with histone deacetylase inhibitors. J Cancer Res Ther. 2014;10(3):469.

136. Barneda-Zahonero B, Parra M. Histone deacetylases and cancer. Mol Oncol. 2012;6(6):579-89.

137. West AC, Johnstone RW. New and emerging HDAC inhibitors for cancer treatment. J Clin Invest. 2014;124(1):30-9.

138. Rajendran P, Ho E, Williams DE, Dashwood RH. Dietary phytochemicals, HDAC inhibition, and DNA damage/repair defects in cancer cells. Clinical epigenetics. 2011;3(1):1.

139. Gray SG, Ekstrom TJ. The human histone deacetylase family. Exp Cell Res. 2001;262(2):75-83.

140. Choudhary C, Kumar C, Gnad F, Nielsen ML, Rehman M, Walther TC, et al. Lysine acetylation targets protein complexes and co-regulates major cellular functions. Science. 2009;325(5942):834-40.

141. Brown JA, Bourke E, Eriksson LA, Kerin MJ. Targeting cancer using KAT inhibitors to mimic lethal knockouts. Biochem Soc Trans. 2016;44(4):979-86.

142. Simon RP, Robaa D, Alhalabi Z, Sippl W, Jung M. KATching-up on small molecule modulators of lysine acetyltransferases. J Med Chem. 2016:59(4):1249-70.

143. Balasubramanyam K, Varier RA, Altaf M, Swaminathan V, Siddappa NB, Ranga U, et al. Curcumin, a novel p300/CREB-binding protein-specific inhibitor of acetyltransferase, represses the acetylation of histone/ nonhistone proteins and histone acetyltransferase-dependent chromatin transcription. J Biol Chem. 2004;279(49):51163-71.

144. Arif M, Vedamurthy BM, Choudhari R, Ostwal YB, Mantelingu K, Kodaganur GS, et al. Nitric oxide-mediated histone hyperacetylation in oral cancer: target for a water-soluble HAT inhibitor, CTK7A. Chemistry \& biology. 2010;17(8):903-13.

145. Sung B, Pandey MK, Ahn KS, Yi T, Chaturvedi MM, Liu M, et al. Anacardic acid (6-nonadecyl salicylic acid), an inhibitor of histone acetyltransferase, suppresses expression of nuclear factor-kB-regulated gene products involved in cell survival, proliferation, invasion, and inflammation through inhibition of the inhibitory subunit of nuclear factor-kBa kinase, leading to potentiation of apoptosis. Blood. 2008;111(10):4880-91.

146. Liu C, Ho PC-L, Wong FC, Sethi G, Wang LZ, Goh BC. Garcinol: current status of its anti-oxidative, anti-inflammatory and anti-cancer effects. Cancer Lett. 2015:362(1):8-14.

147. Balasubramanyam K, Altaf M, Varier RA, Swaminathan V, Ravindran A, Sadhale PP, et al. Polyisoprenylated benzophenone, garcinol, a natural histone acetyltransferase inhibitor, represses chromatin transcription and alters global gene expression. J Biol Chem. 2004;279(32):33716-26.

148. Lai L, Liu J, Zhai D, Lin Q, He L, Dong Y, et al. Plumbagin inhibits tumour angiogenesis and tumour growth through the Ras signalling pathway following activation of the VEGF receptor-2. Br J Pharmacol. 2012;165(4b):1084-96.

149. Ravindra KC, Selvi BR, Arif M, Reddy BA, Thanuja GR, Agrawal S, et al. Inhibition of lysine acetyltransferase KAT3B/p300 activity by a naturally occurring hydroxynaphthoquinone, plumbagin. J Biol Chem. 2009;284(36):24453-64

150. Pan S-T, Qin Y, Zhou Z-W, He Z-X, Zhang $X$, Yang T, et al. Plumbagin suppresses epithelial to mesenchymal transition and stemness via inhibiting Nrf2-mediated signaling pathway in human tongue squamous cell carcinoma cells. Drug Design, Development and Therapy. 2015;9:5511.

151. Wang F, Wang Q, Zhou Z-W, Yu S-N, Pan S-T, He Z-X, et al. Plumbagin induces cell cycle arrest and autophagy and suppresses epithelial to mesenchymal transition involving PI3K/Akt/mTOR-mediated pathway in human pancreatic cancer cells. Drug Design, Development and Therapy. 2015;9:537.

152. Modak R, Basha J, Bharathy N, Maity K, Mizar P, Bhat AV, et al. Probing p300/CBP associated factor (PCAF)-dependent pathways with a small molecule inhibitor. ACS Chem Biol. 2013;8(6):1311-23.

153. Shah P, Djisam R, Damulira H, Aganze A, Danquah M. Embelin inhibits proliferation, induces apoptosis and alters gene expression profiles in breast cancer cells. Pharmacol Rep. 2016;68(3):638-44.

154. Yang T, Lan J, Huang Q, Chen X, Sun X, Yang P, et al. Embelin sensitizes acute myeloid leukemia cells to TRAIL through XIAP inhibition and NF-kB inactivation. Cell Biochem Biophys. 2015;71(1):291-7. 
155. Tohyama S, Tomura A, Ikeda N, Hatano M, Odanaka J, Kubota Y, et al. Discovery and characterization of NK13650s, naturally occurring p300-selective histone acetyltransferase inhibitors. The Journal of organic chemistry. 2012;77(20):9044-52.

156. Bowers EM, Yan G, Mukherjee C, Orry A, Wang L, Holbert MA, et al. Virtual ligand screening of the p300/CBP histone acetyltransferase: identification of a selective small molecule inhibitor. Chemistry \& biology. 2010;17(5):471-82.

157. Santer FR, Höschele PP, Oh SJ, Erb HH, Bouchal J, Cavarretta IT, et al. Inhibition of the acetyltransferases p300 and CBP reveals a targetable function for p300 in the survival and invasion pathways of prostate cancer cell lines. Mol Cancer Ther. 2011;10(9):1644-55.

158. Coffey K, Blackburn TJ, Cook S, Golding BT, Griffin RJ, Hardcastle IR, et al. Characterisation of a Tip60 specific inhibitor, NU9056, in prostate cancer PLoS One. 2012;7(10):e45539.

159. Gao C, Bourke E, Scobie M, Famme MA, Koolmeister T, Helleday T, et al. Rational design and validation of a Tip60 histone acetyltransferase inhibitor. Sci Rep. 2014:4:5372.

160. Rius M, Lyko F. Epigenetic cancer therapy: rationales, targets and drugs. Oncogene. 2011;31(39):4257-65.

161. Benedetti R, Conte M, Iside C, Altucci L. Epigenetic-based therapy: from single- to multi-target approaches. Int J Biochem Cell Biol. 2015;69:121-31.

162. Kaniskan HU, Konze KD, Jin J. Selective inhibitors of protein methyltransferases. J Med Chem. 2014;58(4):1596-629.

163. Miranda TB, Cortez CC, Yoo CB, Liang G, Abe M, Kelly TK, et al. DZNep is a global histone methylation inhibitor that reactivates developmental genes not silenced by DNA methylation. Mol Cancer Ther. 2009;8(6):1579-88.

164. Borchardt R, Keller B, Patel-Thombre U, Neplanocin A. A potent inhibitor of S-adenosylhomocysteine hydrolase and of vaccinia virus multiplication in mouse L929 cells. J Biol Chem. 1984;259(7):4353-8.

165. Hayden A, Johnson PW, Packham G, Crabb SJ. S-adenosylhomocysteine hydrolase inhibition by 3-deazaneplanocin A analogues induces anti-cancer effects in breast cancer cell lines and synergy with both histone deacetylase and HER2 inhibition. Breast Cancer Res Treat. 2011;127(1):109-19.

166. Lee J-K, Kim K-C. DZNep, inhibitor of S-adenosylhomocysteine hydrolase, down-regulates expression of SETDB1 H3K9me3 HMTase in human lung cancer cells. Biochem Biophys Res Commun. 2013;438(4):647-52.

167. Diaz E, Machutta CA, Chen S, Jiang Y, Nixon C, Hofmann G, et al. Development and validation of reagents and assays for $\mathrm{EZH} 2$ peptide and nucleosome high-throughput screens. J Biomol Screen. 2012;17(10):1279-92.

168. McCabe MT, Ott HM, Ganji G, Korenchuk S, Thompson C, Van Aller GS, et al. EZH2 inhibition as a therapeutic strategy for lymphoma with EZH2-activating mutations. Nature. 2012;492(7427):108-12.

169. Sato T, Kaneda A, Tsuji S, Isagawa T, Yamamoto S, Fujita T, et al. PRC2 overexpression and PRC2-target gene repression relating to poorer prognosis in small cell lung cancer. Sci Rep. 2013;3:1911.

170. Tiffen JC, Gunatilake D, Gallagher SJ, Gowrishankar K, Heinemann A, Cullinane C, et al. Targeting activating mutations of EZH2 leads to potent cell growth inhibition in human melanoma by derepression of tumor suppressor genes. Oncotarget. 2015;6(29):27023-36.

171. Knutson SK, Kawano S, Minoshima Y, Warholic NM, Huang K-C, Xiao Y, et al. Selective inhibition of EZH2 by EPZ-6438 leads to potent antitumor activity in EZH2-mutant non-Hodgkin lymphoma. Mol Cancer Ther. 2014;13(4):842-54.

172. Mimasu S, Sengoku T, Fukuzawa S, Umehara T, Yokoyama S. Crystal structure of histone demethylase LSD1 and tranylcypromine at $2.25 \AA$ Biochem Biophys Res Commun. 2008;366(1):15-22.

173. Suzuki T, Miyata N. Lysine demethylases inhibitors. J Med Chem. 2011;54(24):8236-50

174. Benelkebir H, Hodgkinson C, Duriez PJ, Hayden AL, Bulleid RA, Crabb SJ, et al. Enantioselective synthesis of tranylcypromine analogues as lysine demethylase (LSD1) inhibitors. Bioorg Med Chem. 2011;19(12):3709-16.

175. Willmann D, Lim S, Wetzel S, Metzger E, Jandausch A, Wilk W, et al. Impairment of prostate cancer cell growth by a selective and reversible lysine-specific demethylase 1 inhibitor. Int J Cancer. 2012;131(11):2704-9.

176. Yang Z, He N, Zhou Q. Brd4 recruits P-TEFb to chromosomes at late mitosis to promote $\mathrm{G} 1$ gene expression and cell cycle progression. Mol Cell Biol. 2008;28(3):967-76.

177. Ferri E, Petosa C, McKenna CE. Bromodomains: structure, function and pharmacology of inhibition. Biochem Pharmacol. 2015;106:1-18.
178. Conery AR, Centore RC, Spillane KL, Follmer NE, Bommi-Reddy A, Hatton C, et al. Preclinical anticancer efficacy of BET bromodomain inhibitors is determined by the apoptotic response. Cancer Res. 2016;76:1313-9.

179. Garcia P, Miller A, Kreitzburg K, Council L, Gamblin T, Christein J, et al. The BET bromodomain inhibitor JQ1 suppresses growth of pancreatic ductal adenocarcinoma in patient-derived xenograft models. Oncogene. 2015. doi:10.1038/onc.2015.126.

180. Li G-Q, Guo W-Z, Zhang Y, Seng J-J, Zhang H-P, Ma X-X, et al. Suppression of BRD4 inhibits human hepatocellular carcinoma by repressing MYC and enhancing BIM expression. Oncotarget. 2015;7:2462-74.

181. Ambrosini G, Sawle AD, Musi E, Schwartz GK. BRD4-targeted therapy induces Myc-independent cytotoxicity in Gnaq/11-mutatant uveal melanoma cells. Oncotarget. 2015;6(32):33397-409.

182. Chaidos A, Caputo V, Gouvedenou K, Liu B, Marigo I, Chaudhry MS, et al. Potent antimyeloma activity of the novel bromodomain inhibitors I-BET151 and I-BET762. Blood. 2014;123(5):697-705.

183. Asangani IA, Dommeti VL, Wang X, Malik R, Cieslik M, Yang $R$, et al. Therapeutic targeting of BET bromodomain proteins in castration-resistant prostate cancer. Nature. 2014;510:278-82.

184. Coudé M-M, Braun T, Berrou J, Dupont M, Bertrand S, Masse A, et al. BET inhibitor OTX015 targets BRD2 and BRD4 and decreases c-MYC in acute leukemia cells. Oncotarget. 2015;6:17698-712.

185. Boi M, Gaudio E, Bonetti P, Kwee I, Bernasconi E, Tarantelli C, et al. The BET bromodomain inhibitor OTX015 affects pathogenetic pathways in preclinical B-cell tumor models and synergizes with targeted drugs. Clin Cancer Res. 2015;21(7):1628-38.

186. Picaud S, Fedorov O, Thanasopoulou A, Leonards K, Jones K, Meier J, et al. Generation of a selective small molecule inhibitor of the CBP/p300 bromodomain for leukemia therapy. Cancer Res. 2015;75(23):5106-19.

187. Zucconi BE, Luef B, Xu W, Henry RA, Nodelman IM, Bowman GD, et al. Modulation of p300/CBP acetylation of nucleosomes by bromodomain ligand I-CBP112. Biochemistry. 2016;55(27):3727-34.

188. Huang H, Reed CP, Zhang JS, Shridhar V, Wang L, Smith DI. Carboxypeptidase A3 (CPA3): a novel gene highly induced by histone deacetylase inhibitors during differentiation of prostate epithelial cancer cells. Cancer Res. 1999:59(12):2981-8.

189. Mu D, Gao Z, Guo H, Zhou G, Sun B. Sodium butyrate induces growth inhibition and apoptosis in human prostate cancer DU145 cells by up-regulation of the expression of annexin A1. PLoS One. 2013;8(9):e74922.

190. Cang S, Xu X, Ma Y, Liu D, Chiao J. Hypoacetylation, hypomethylation, and dephosphorylation of $\mathrm{H} 2 \mathrm{~B}$ histones and excessive histone deacetylase activity in DU-145 prostate cancer cells. J Hematol Oncol. 2016;9(1):1-4.

191. Weaver EM, Zamora FJ, Puplampu-Dove YA, Kiessu E, Hearne JL, Martin-Caraballo M. Regulation of T-type calcium channel expression by sodium butyrate in prostate cancer cells. Eur J Pharmacol. 2015;749:20-31.

192. Shabbeer S, Kortenhorst MS, Kachhap S, Galloway N, Rodriguez R, Carducci MA. Multiple Molecular pathways explain the anti-proliferative effect of valproic acid on prostate cancer cells in vitro and in vivo. Prostate. 2007;67(10):1099-110.

193. Lan X, Lu G, Yuan C, Mao S, Jiang W, Chen Y, et al. Valproic acid (VPA) inhibits the epithelial-mesenchymal transition in prostate carcinoma via the dual suppression of SMAD4. J Cancer Res Clin Oncol. 2016;142(1):177-85.

194. Lee JE, Kim JH. Valproic acid inhibits the invasion of PC3 prostate cancer cells by upregulating the metastasis suppressor protein NDRG1. Genet Mol Biol. 2015;38(4):527-33.

195. Witt D, Burfeind P, von Hardenberg S, Opitz L, Salinas-Riester G, Bremer F, et al. Valproic acid inhibits the proliferation of cancer cells by re-expressing cyclin D2. Carcinogenesis. 2013. doi:10.1093/carcin/bgt019.

196. Chou Y-W, Chaturvedi NK, Ouyang S, Lin F-F, Kaushik D, Wang J, et al. Histone deacetylase inhibitor valproic acid suppresses the growth and increases the androgen responsiveness of prostate cancer cells. Cancer Lett. 2011;311(2):177-86.

197. Lakshmikanthan V, Kaddour-Djebbar I, Lewis RW, Kumar MV. SAHAsensitized prostate cancer cells to TNFalpha-related apoptosis-inducing ligand (TRAIL): mechanisms leading to synergistic apoptosis. Int J Cancer. 2006;119(1):221-8.

198. Butler LM, Agus DB, Scher HI, Higgins B, Rose A, Cordon-Cardo C, et al. Suberoylanilide hydroxamic acid, an inhibitor of histone deacetylase, suppresses the growth of prostate cancer cells in vitro and in vivo. Cancer Res. 2000;60(18):5165-70. 
199. Pettazzoni P, Pizzimenti S, Toaldo C, Sotomayor P, Tagliavacca L, Liu S, et al. Induction of cell cycle arrest and DNA damage by the HDAC inhibitor panobinostat (LBH589) and the lipid peroxidation end product 4-hydroxynonenal in prostate cancer cells. Free Radic Biol Med. 2011;50(2):313-22.

200. Liu X, Gomez-Pinillos A, Liu X, Johnson EM, Ferrari AC. Induction of bicalutamide sensitivity in prostate cancer cells by an epigenetic Pura-mediated decrease in androgen receptor levels. Prostate. 2010; 70(2):179-89.

201. Sante D. Differential effects of PXD101 (belinostat) on androgen-dependent and androgen-independent prostate cancer models. Int J Oncol. 2012;40(3):711-20.

202. Qian X, Ara G, Mills E, LaRochelle WJ, Lichenstein HS, Jeffers M. Activity of the histone deacetylase inhibitor belinostat (PXD101) in preclinical models of prostate cancer. Int J Cancer. 2008;122(6):1400-10.

203. Lai MT, Yang CC, Lin TY, Tsai FJ, Chen WC. Depsipeptide (FK228) inhibits growth of human prostate cancer cells. Urol Oncol. 2008;26(2):182-9.

204. Wang B, Huang P-H, Chen C-S, Forsyth CJ. Total syntheses of the histone deacetylase inhibitors largazole and 2-epi-largazole: application of $\mathrm{N}$-heterocyclic carbene mediated acylations in complex molecule synthesis. J Org Chem. 2011;76(4):1140-50.

205. Qian DZ, Wei YF, Wang X, Kato Y, Cheng L, Pili R. Antitumor activity of the histone deacetylase inhibitor MS-275 in prostate cancer models. Prostate. 2007;67(11):1182-93.

206. Camphausen K, Scott T, Sproull M, Tofilon PJ. Enhancement of xenograft tumor radiosensitivity by the histone deacetylase inhibitor MS-275 and correlation with histone hyperacetylation. Clin Cancer Res. 2004;10(18):6066-71.

207. Huang P-H, Chen C-H, Chou C-C, Sargeant AM, Kulp SK, Teng C-M, et al. Histone deacetylase inhibitors stimulate histone $\mathrm{H} 3$ lysine 4 methylation in part via transcriptional repression of histone $\mathrm{H} 3$ lysine 4 demethylases. Mol Pharmacol. 2011;79(1):197-206.

208. Myzak MC, Tong P, Dashwood W-M, Dashwood RH, Ho E. Sulforaphane retards the growth of human $P C-3$ xenografts and inhibits HDAC activity in human subjects. Exp Biol Med. 2007;232(2):227-34.

209. Clarke JD, Hsu A, Yu Z, Dashwood RH, Ho E. Differential effects of sulforaphane on histone deacetylases, cell cycle arrest and apoptosis in normal prostate cells versus hyperplastic and cancerous prostate cells. Mol Nutr Food Res. 2011;55(7):999-1009.

210. Gibbs A, Schwartzman J, Deng V, Alumkal J. Sulforaphane destabilizes the androgen receptor in prostate cancer cells by inactivating histone deacetylase 6. Proc Natl Acad Sci. 2009;106(39):16663-8.

211. Vyas AR, Moura MB, Hahm ER, Singh KB, Singh SV. Sulforaphane inhibits c-Myc-mediated prostate cancer stem-like traits. J Cell Biochem. 2016. doi:10.1002/jcb.25541.

212. Powolny AA, Bommareddy A, Hahm E-R, Normolle DP, Beumer JH, Nelson JB, et al. Chemopreventative potential of the cruciferous vegetable constituent phenethyl isothiocyanate in a mouse model of prostate cancer. J Natl Cancer Inst. 2011;103(7):571-84.

213. Hudson TS, Perkins SN, Hursting SD, Young HA, Kim YS, Wang T-C, et al. Inhibition of androgen-responsive LNCaP prostate cancer cell tumor xenograft growth by dietary phenethyl isothiocyanate correlates with decreased angiogenesis and inhibition of cell attachment. Int J Oncol. 2012;40(4):1113-21.

214. Sakao K, Desineni S, Hahm ER, Singh SV. Phenethyl isothiocyanate suppresses inhibitor of apoptosis family protein expression in prostate cancer cells in culture and in vivo. Prostate. 2012;72(10):1104-16.

215. Tang N-Y, Huang Y-T, Yu C-S, Ko Y-C, Wu S-H, Ji B-C, et al. Phenethyl isothiocyanate (PEITC) promotes G2/M phase arrest via p53 expression and induces apoptosis through caspase-and mitochondria-dependent signaling pathways in human prostate cancer DU 145 cells. Anticancer Res. 2011;31(5):1691-702.

216. Zhang C, Shu L, Kim H, Khor TO, Wu R, Li W, et al. Phenethyl isothiocyanate (PEITC) suppresses prostate cancer cell invasion epigenetically through regulating microRNA-194. Mol Nutr Food Res. 2016;60(6):1427-36.

217. Wang L, Liu X, Chiao J. Repression of androgen receptor in prostate cancer cells by phenethyl isothiocyanate. Carcinogenesis. 2006;27(10):2124-32.

218. Sun Q, Yao Y, Liu C, Li H, Yao H, Xue X, et al. Design, synthesis, and biological evaluation of novel histone deacetylase 1 inhibitors through click chemistry. Bioorg Med Chem Lett. 2013;23(11):3295-9.
219. Lee J-H, Mahendran A, Yao Y, Ngo L, Venta-Perez G, Choy ML, et al. Development of a histone deacetylase 6 inhibitor and its biological effects. Proc Natl Acad Sci. 2013;110(39):15704-9.

220. Patil V, Sodji QH, Kornacki JR, Mrksich M, Oyelere AK. 3-Hydroxypyridin-2thione as novel zinc binding group for selective histone deacetylase inhibition. J Med Chem. 2013;56(9):3492-506.

221. Kong Y, Jung M, Wang K, Grindrod S, Velena A, Lee SA, et al. Histone deacetylase cytoplasmic trapping by a novel fluorescent HDAC inhibitor. Mol Cancer Ther. 2011;10(9):1591-9.

222. Thanh Tung T, Thi Kim Oanh D, Thi Phuong Dung P, Thi My Hue V, Ho Park S, Woo Han B, et al. New benzothiazole/thiazole-containing hydroxamic acids as potent histone deacetylase inhibitors and antitumor agents. Med Chem. 2013;9(8):1051-7.

223. Gryder BE, Akbashev MJ, Rood MK, Raftery ED, Meyers WM, Dillard P, et al. Selectively targeting prostate cancer with antiandrogen equipped histone deacetylase inhibitors. ACS Chem Biol. 2013;8(11):2550-60.

224. Carrasco MP, Enyedy EA, Krupenko NI, Krupenko SA, Nuti E, Tuccinardi T, et al. Novel folate-hydroxamate based antimetabolites: synthesis and biological evaluation. Med Chem. 2011;7(4):265-74.

225. Peng Z-H, Kopeček J. Synthesis and activity of tumor-homing peptide iRGD and histone deacetylase inhibitor valproic acid conjugate. Bioorg Med Chem Lett. 2014;24(8):1928-33.

226. Zhang $X$, Bao B, Yu X, Tong L, Luo Y, Huang Q, et al. The discovery and optimization of novel dual inhibitors of topoisomerase II and histone deacetylase. Bioorg Med Chem. 2013;21(22):6981-95.

227. Yu C-C, Pan S-L, Chao S-W, Liu S-P, Hsu J-L, Yang Y-C, et al. A novel small molecule hybrid of vorinostat and DACA displays anticancer activity against human hormone-refractory metastatic prostate cancer through dual inhibition of histone deacetylase and topoisomerase I. Biochem Pharmacol. 2014;90(3):320-30

228. Cai X, Zhai H-X, Wang J, Forrester J, Qu H, Yin L, et al. Discovery of 7-(4-(3ethynylphenylamino)-7-methoxyquinazolin-6-yloxy)-N-hydroxyheptanamide (CUDC-101) as a potent multi-acting HDAC, EGFR, and HER2 inhibitor for the treatment of cancer. J Med Chem. 2010;53(5):2000-9.

229. Sun H, Mediwala SN, Szafran AT, Mancini MA, Marcelli M. CUDC-101, a novel inhibitor of full-length androgen receptor (fIAR) and androgen receptor variant 7 (AR-V7) activity: mechanism of action and in vivo efficacy. Horm Cancer. 2016;7(3):196-210.

230. Bradley D, Rathkopf D, Dunn R, Stadler WM, Liu G, Smith DC, et al. Vorinostat in advanced prostate cancer patients progressing on prior chemotherapy (National Cancer Institute Trial 6862). Cancer. 2009;115(23):5541-9.

231. Rathkopf DE, Picus J, Hussain A, Ellard S, Chi KN, Nydam T, et al. A phase 2 study of intravenous panobinostat in patients with castration-resistant prostate cancer. Cancer Chemother Pharmacol. 2013;72(3):537-44.

232. Molife L, Attard G, Fong P, Karavasilis V, Reid A, Patterson S, et al. Phase II, two-stage, single-arm trial of the histone deacetylase inhibitor (HDACi) romidepsin in metastatic castration-resistant prostate cancer (CRPC). Ann Oncol. 2010;21(1):109-13.

233. Eigl B, North S, Winquist E, Finch D, Wood L, Sridhar S, et al. A phase II study of the HDAC inhibitor SB939 in patients with castration resistant prostate cancer: NCIC clinical trials group study IND195. Investig New Drugs. 2015;33(4):969-76

234. Alumkal JJ, Slottke R, Schwartzman J, Cherala G, Munar M, Graff JN, et al. A phase II study of sulforaphane-rich broccoli sprout extracts in men with recurrent prostate cancer. Investig New Drugs. 2015;33(2):480-9.

235. Cipolla BG, Mandron E, Lefort JM, Coadou Y, Della Negra E, Corbel L, et al. Effect of sulforaphane in men with biochemical recurrence after radical prostatectomy. Cancer Prev Res. 2015;8(8):712-9.

236. Hu HJ, Lin XL, Liu MH, Fan XJ, Zou WW. Curcumin mediates reversion of HGF-induced epithelial-mesenchymal transition via inhibition of c-Met expression in DU145 cells. Oncol Lett. 2016;11(2):1499-505.

237. Killian PH, Kronski E, Michalik KM, Barbieri O, Astigiano S, Sommerhoff CP, et al. Curcumin inhibits prostate cancer metastasis in vivo by targeting the inflammatory cytokines CXCL1 and-2. Carcinogenesis. 2012. doi:10.1093/carcin/bgs312.

238. Shu L, Khor TO, Lee J-H, Boyanapalli SS, Huang Y, Wu T-Y, et al. Epigenetic $\mathrm{CpG}$ demethylation of the promoter and reactivation of the expression of Neurog1 by curcumin in prostate LNCaP cells. AAPS J. 2011;13(4):606-14.

239. Wu M, Kim S-H, Datta I, Levin A, Dyson G, Li J, et al. Hydrazinobenzoylcurcumin inhibits androgen receptor activity and growth of castration-resistant prostate cancer in mice. Oncotarget. 2015;6(8):6136. 
240. Tan J, Chen B, He L, Tang Y, Jiang Z, Yin G, et al. Anacardic acid (6-pentadecylsalicylic acid) induces apoptosis of prostate cancer cells through inhibition of androgen receptor and activation of p53 signaling. Chin J Cancer Res. 2012;24(4):275-83.

241. Wang $Y$, Tsai M-L, Chiou L-Y, Ho C-T, Pan M-H. Antitumor activity of garcinol in human prostate cancer cells and xenograft mice. J Agric Food Chem. 2015;63(41):9047-52

242. Ahmad A, Wang Z, Wojewoda C, Ali R, Kong D, Maitah M, et al. Garcinol-induced apoptosis in prostate and pancreatic cancer cells is mediated by NF-kappaB signaling. Front Biosci (Elite Ed). 2010;3:1483-92.

243. Zhou Z-W, Li X-X, He Z-X, Pan S-T, Yang Y, Zhang X, et al. Induction of apoptosis and autophagy via sirtuin1-and PI3K/Akt/mTOR-mediated pathways by plumbagin in human prostate cancer cells. Drug Des Devel Ther. 2015;9:1511.

244. Reshma R, Sreelatha K, Somasundaram V, Nadhan R, Nair RS, Srinivas P. Plumbagin, a naphthaquinone derivative induces apoptosis in BRCA 1/2 defective castrate resistant prostate cancer cells as well as prostate cancer stem-like cells. Pharmacol Res. 2016;105:134-45.

245. Park N, Baek HS, Chun Y-J. Embelin-induced apoptosis of human prostate cancer cells is mediated through modulation of Akt and $\beta$-Catenin signaling. PLoS One. 2015;10(8):e0134760.

246. Kim SW, Kim SM, Bae H, Nam D, Lee JH, Lee SG, et al. Embelin inhibits growth and induces apoptosis through the suppression of Akt/mTOR/S6K1 signaling cascades. Prostate. 2013;73(3):296-305.

247. Dai Y, DeSano J, Qu Y, Tang W, Meng Y, Lawrence TS, et al. Natural IAP inhibitor Embelin enhances therapeutic efficacy of ionizing radiation in prostate cancer. Am J Cancer Res. 2011;1:128-43.

248. Danquah M, Duke III CB, Patil R, Miller DD, Mahato RI. Combination therapy of antiandrogen and XIAP inhibitor for treating advanced prostate cancer. Pharm Res. 2012;29(8):2079-91.

249. Halkidou K, Gnanapragasam VJ, Mehta PB, Logan IR, Brady ME, Cook S, et al. Expression of Tip60, an androgen receptor coactivator, and its role in prostate cancer development. Oncogene. 2003;22(16):2466-77.

250. Crea F, Hurt EM, Mathews LA, Cabarcas SM, Sun L, Marquez VE, et al. Pharmacologic disruption of polycomb repressive complex 2 inhibits tumorigenicity and tumor progression in prostate cancer. Mol Cancer. 2011;10(1):40.

251. Wu C, Jin X, Yang J, Yang Y, He Y, Ding L, et al. Inhibition of EZH2 by chemo-and radiotherapy agents and small molecule inhibitors induces cell death in castration-resistant prostate cancer. Oncotarget. 2015.

252. Knutson SK, Wigle TJ, Warholic NM, Sneeringer CJ, Allain CJ, Klaus CR, et al. A selective inhibitor of EZH2 blocks H3K27 methylation and kills mutant lymphoma cells. Nat Chem Biol. 2012;8(11):890-6.

253. Sweis RF, Pliushchev M, Brown PJ, Guo J, Li F, Maag D, et al. Discovery and development of potent and selective inhibitors of histone methyltransferase g9a. ACS Med Chem Lett. 2014;5(2):205-9.

254. Cheng D, Valente S, Castellano S, Sbardella G, Di Santo R, Costi R, et al. Novel 3, 5-bis (bromohydroxybenzylidene) piperidin-4-ones as coactivator-associated arginine methyltransferase 1 inhibitors: enzyme selectivity and cellular activity. J Med Chem. 2011;54(13):4928-32.

255. Wang M, Liu X, Guo J, Weng X, Jiang G, Wang Z, et al. Inhibition of LSD1 by Pargyline inhibited process of EMT and delayed progression of prostate cancer in vivo. Biochem Biophys Res Commun. 2015;467(2):310-5.

256. Lee HT, Choi MR, Doh MS, Jung KH, Chai YG. Effects of the monoamine oxidase inhibitors pargyline and tranylcypromine on cellular proliferation in human prostate cancer cells. Oncol Rep. 2013;30(4):1587-92.

257. Rotili D, Tomassi S, Conte M, Benedetti R, Tortorici M, Ciossani G, et al. Pan-histone demethylase inhibitors simultaneously targeting Jumonji $C$ and lysine-specific demethylases display high anticancer activities. J Med Chem. 2013;57(1):42-55.

258. Wyce A, Degenhardt Y, Bai Y, Le B, Korenchuk S, Crouthamel M-C, et al. Inhibition of BET bromodomain proteins as a therapeutic approach in prostate cancer. Oncotarget. 2013;4(12):2419.

259. Fialova B, Smesny Trtkova K, Paskova L, Langova K, Kolar Z. Effect of histone deacetylase and DNA methyltransferase inhibitors on the expression of the androgen receptor gene in androgen-independent prostate cancer cell lines. Oncol Rep. 2013;29(5):2039-45.

260. Festuccia C, Gravina GL, D'Alessandro AM, Muzi P, Millimaggi D, Dolo V, et al. Azacitidine improves antitumor effects of docetaxel and cisplatin in aggressive prostate cancer models. Endocr Relat Cancer. 2009;16(2):401-13.

261. Takeshima H, Wakabayashi M, Hattori N, Yamashita S, Ushijima T. Identification of coexistence of DNA methylation and H3K27me3 specifically in cancer cells as a promising target for epigenetic therapy. Carcinogenesis. 2015;36(2):192-201.
262. Chao OS, Goodman OB. Synergistic loss of prostate cancer cell viability by coinhibition of HDAC and PARP. Mol Cancer Res. 2014;12(12):1755-66.

263. Chinnaiyan P, Vallabhaneni G, Armstrong E, Huang S-M, Harari PM. Modulation of radiation response by histone deacetylase inhibition. Int J Radiat Oncol Biol Phys. 2005;62(1):223-9.

264. Sonnemann J, Bumbul B, Beck JF. Synergistic activity of the histone deacetylase inhibitor suberoylanilide hydroxamic acid and the bisphosphonate zoledronic acid against prostate cancer cells in vitro. Mol Cancer Ther. 2007;6(11):2976-84.

265. Marrocco DL, Tilley WD, Bianco-Miotto T, Evdokiou A, Scher HI, Rifkind RA, et al. Suberoylanilide hydroxamic acid (vorinostat) represses androgen receptor expression and acts synergistically with an androgen receptor antagonist to inhibit prostate cancer cell proliferation. Mol Cancer Ther. 2007;6(1):51-60.

266. Xiao W, Graham PH, Hao J, Chang L, Ni J, Power CA, et al. Combination therapy with the histone deacetylase inhibitor LBH589 and radiation is an effective regimen for prostate cancer cells. PLoS One. 2013;8(8):e74253.

267. Kanzaki M, Kakinuma H, Kumazawa T, Inoue T, Saito M, Narita S, et al. Low concentrations of the histone deacetylase inhibitor, depsipeptide, enhance the effects of gemcitabine and docetaxel in hormone refractory prostate cancer cells. Oncol Rep. 2007;17(4):761-8.

268. Zhang Z, Stanfield J, Frenkel E, Kabbani W, Hsieh JT. Enhanced therapeutic effect on androgen-independent prostate cancer by depsipeptide (FK228), a histone deacetylase inhibitor, in combination with docetaxel. Urology. 2007 ; 70(2):396-401

269. Khurana N, Talwar S, Chandra PK, Sharma P, Abdel-Mageed AB, Mondal D, et al. Sulforaphane increases the efficacy of anti-androgens by rapidly decreasing androgen receptor levels in prostate cancer cells. Int J Oncol. 2016. doi:10.3892/ijo.2016.3641.

270. Yao K, Jiang X. Anacardic acid sensitizes prostate cancer cells to radiation therapy by regulating $\mathrm{H} 2 \mathrm{AX}$ expression. Int J Clin Exp Pathol. 2015;8(12):15926.

271. Asangani IA, Wilder-Romans K, Dommeti VL, Krishnamurthy PM, Apel IJ, Escara-Wilke J, et al. BET bromodomain inhibitors enhance efficacy and disrupt resistance to AR antagonists in the treatment of prostate cancer. Mol Cancer Res. 2016;14(4):324-31.

272. Nebbioso A, Pereira R, Khanwalkar H, Matarese F, García-Rodríquez J, Miceli $\mathrm{M}$, et al. Death receptor pathway activation and increase of ROS production by the triple epigenetic inhibitor UVI5008. Mol Cancer Ther. 2011;10(12):2394-404

273. Singal R, Ramachandran K, Gordian E, Quintero C, Zhao W, Reis IM. Phase I/I study of azacitidine, docetaxel, and prednisone in patients with metastatic castration-resistant prostate cancer previously treated with docetaxel-based therapy. Clin Genitourin Cancer. 2015;13(1):22-31.

274. Schneider BJ, Kalemkerian GP, Bradley D, Smith DC, Egorin MJ, Daignault S, et al. Phase I study of vorinostat (suberoylanilide hydroxamic acid, NSC 701852) in combination with docetaxel in patients with advanced and relapsed solid malignancies. Investig New Drugs. 2012;30(1):249-57.

275. Munster PN, Marchion D, Thomas S, Egorin M, Minton S, Springett G, et al. Phase I trial of vorinostat and doxorubicin in solid tumours: histone deacetylase 2 expression as a predictive marker. $\mathrm{Br} J$ Cancer. 2009;101(7):1044-50.

276. Rathkopf D, Wong BY, Ross RW, Anand A, Tanaka E, Woo MM, et al. A phase I study of oral panobinostat alone and in combination with docetaxel in patients with castration-resistant prostate cancer. Cancer Chemother Pharmacol. 2010:66(1):181-9.

277. Ferrari AC, Stein MN, Alumkal JJ, Gomez-Pinillos A, Catamero DD, Mayer TM, Collins F, Beer TM, DiPaola RS. A phase $\mathrm{I} / \mathrm{Il}$ randomized study of panobinostat and bicalutamide in castration-resistant prostate cancer (CRPC) patients progressing on second-line hormone therapy. J Clin Oncol. 2011 [Epub ahead of print].

278. Wheler JJ, Janku F, Falchook GS, Jackson TL, Fu S, Naing A, et al. Phase I study of anti-VEGF monoclonal antibody bevacizumab and histone deacetylase inhibitor valproic acid in patients with advanced cancers. Cancer Chemother Pharmacol. 2014;73(3):495-501.

279. Mahammedi H, Planchat E, Pouget M, Durando X, Cure H, Guy L, et al. The new combination docetaxel, prednisone and curcumin in patients with castration-resistant prostate cancer: a pilot phase II study. Oncology. 2016. doi:10.1159/000441148.

280. Hejazi J, Rastmanesh R, Taleban F-A, Molana S-H, Ehtejab G. A pilot clinical trial of radioprotective effects of curcumin supplementation in patients with prostate cancer. J Cancer Sci Ther. 2013;5:320-4. 
281. Yoo CB, Jones PA. Epigenetic therapy of cancer: past, present and future. Nat Rev Drug Discov. 2006;5(1):37-50.

282. Liang Y, Li XY, Rebar EJ, Li P, Zhou Y, Chen B, et al. Activation of vascular endothelial growth factor A transcription in tumorigenic glioblastoma cell lines by an enhancer with cell type-specific DNase I accessibility. J Biol Chem. 2002;277(22):20087-94.

283. Fan H, Lu X, Wang X, Liu Y, Guo B, Zhang Y, et al. Low-dose decitabine-based chemoimmunotherapy for patients with refractory advanced solid tumors: a phase I/II report. J Immunol Res. 2014;2014:371087.

Submit your next manuscript to BioMed Central and we will help you at every step:

- We accept pre-submission inquiries

- Our selector tool helps you to find the most relevant journal

- We provide round the clock customer support

- Convenient online submission

- Thorough peer review

- Inclusion in PubMed and all major indexing services

- Maximum visibility for your research

Submit your manuscript at www.biomedcentral.com/submit
Biomed Central 